4

5

6

7

8

9

13

14

15 7

\title{
Observed modes of sea surface temperature variability in the South Pacific region
}

\author{
Ramiro I. Saurral ${ }^{1}$, Francisco J. Doblas-Reyes ${ }^{2,3}$ and Javier García-Serrano ${ }^{2}$ \\ ${ }^{1}$ Centro de Investigaciones del Mar y la Atmósfera (CIMA; UBA-CONICET), UMI- \\ IFAECI/CNRS, and Departamento de Ciencias de la Atmósfera y los Océanos (DCAO; \\ FCEN, UBA), Buenos Aires, Argentina \\ ${ }^{2}$ Barcelona Supercomputing Center (BSC), Barcelona, Spain \\ ${ }^{3}$ Institució Catalana de Recerca i Estudis Avançats (ICREA), Barcelona, Spain
} (1)

Corresponding author:

Ramiro I. Saurral

CIMA and DCAO

Int. Güiraldes 2160, Ciudad Universitaria, Pab. 2 (C1428EGA)

Buenos Aires

Argentina

E-mail: $\underline{\text { saurral@ cima.fcen.uba.ar }}$

Phone/fax number: +54-11-4576-3398 
The South Pacific (SP) region exerts large control on the climate of the Southern

Hemisphere at many times scales. This paper identifies the main modes of interannual sea surface temperature (SST) variability in the SP which consist of a tropical-driven mode related to a horseshoe structure of positive/negative SST anomalies within midlatitudes and highly correlated to ENSO and Interdecadal Pacific Oscillation (IPO) variability, and another mode mostly confined to extratropical latitudes which is characterized by zonal propagation of SST anomalies within the South Pacific Gyre.

Both modes are associated with temperature and rainfall anomalies over the continental regions of the Southern Hemisphere. Besides the leading mode which is related to well known warmer/cooler and drier/moister conditions due to its relationship with ENSO and the IPO, an inspection of the extratropical mode indicates that it is associated with distinct patterns of sea level pressure and surface temperature advection. These relationships are used here as plausible and partial explanations to the observed warming trend observed within the Southern Hemisphere during the last decades.

Keywords: South Pacific; Southern Hemisphere warming; IPO; ENSO; CEOF analysis 


\section{Introduction}

Most of the scientific literature on climate variability within the Pacific region focuses on the tropical belt where the amplitude of El Niño-Southern Oscillation (ENSO) is largest and also on the North Pacific, mainly due to its effects over North America (e.g. Latif and Barnett 1994; Gershunou et al. 1999; Hurwitz et al. 2012; Lienert and Doblas-Reyes 2013). However, considerably less attention has been devoted to the South Pacific (SP) in spite of its significant role on the climate of the Southern Hemisphere. Morioka et al. (2013) suggest that this issue may be attributed to the lack of long-term in situ data over that region where sufficient basin-wide information exists only since the 1980s (their Fig. 1).

The SP basin, considered in this study as the region extending from Australia to the west and South America to the east, and from $20^{\circ} \mathrm{S}$ to $65^{\circ} \mathrm{S}$ (Fig. 1), encompasses the largest oceanic gyre in the world, the South Pacific Gyre, and is characterized by pronounced oscillations on intra- to multi-seasonal (Guan et al. 2014) and on interannual and longer (Karoly et al. 1989; White and Peterson 1996; Linsley et al. 2000) time scales. These oscillations are tightly related to sea surface temperature (SST) variability in the equatorial Pacific region (Kidson and Renwick 2002; Shakun and Shaman 2009) through the PacificSouth American (PSA) mode (Karoly et al. 1989) but are also connected to higher latitudes via the Antarctic Circumpolar Wave (ACW; White and Peterson 1996). In fact, Peterson and White (1998) showed that SST anomalies that feed the ACW actually originate in the western subtropical SP region, while White et al. (2002) concluded that there is a positive feedback between the ACW and ENSO through propagation of SST anomalies within the SP and Indian Ocean basins. At lower frequencies, a recent paper by Tatebe et al. (2013) 
shows that decadal and bi-decadal variability in the tropical Pacific have their origin in subsurface temperature anomalies over the SP.

Of the various modes of climate variability that impact the SP region, ENSO and the Interdecadal Pacific Oscillation (IPO; Power et al. 1999) are those which explain the largest portion of variance on interannual to interdecadal time scales (Linsley et al. 2000; Shakun and Shaman 2009). However, more research is needed to fully characterize the other dominant modes of SST variability in this basin.

Among the few papers dealing with the SP region, Barros and Silvestri (2002) studied the joint variability of SST in the subtropical SP and precipitation over southeastern South America and concluded that SST oscillations explain almost $25 \%$ of the variance of rainfall over the continent during late austral spring even in the absence of El Niño or La Niña. Montecinos and Pizarro (2005) used Combined Complex Empirical Orthogonal Functions (CCEOF) to analyze the covariability of SST and sea level pressure (SLP) anomalies over the SP and found how decadal to bi-decadal SST variability over the western coasts of South America is related to zonal wind stress anomalies over the tropical Pacific. More recently, Ballester et al. (2011) reported that SST anomalies over selected regions within the SP can be used as precursors to the onset of El Niño and La Niña events. They defined a dipole index using SST anomalies in two regions to the north of the Ross and Bellingshausen Seas and concluded that the intensity of the dipole can be used to predict the onset of ENSO events almost 9 months in advance. Morioka et al. (2013) used observations as well as simulations performed with a coupled GCM to prove that interannual SST variability in the SP region is partly controlled by changes in the depth of the oceanic mixed layer, which alter the intensity of the sensible/latent heat fluxes towards the atmosphere and thus the SST anomalies. They also found a relationship with the 
location of specific centers of SLP anomalies which act to strengthen this process. Salinger et al. (2001) characterized the linkage between the IPO and surface pressure, temperature and rainfall anomalies over the southwestern SP region.

The non-stationary nature of the IPO has also affected the SP region in the last decades. Recently, Jacques-Copper and Garreaud (2015) identified the changes in surface air temperature, SLP and precipitation before and after the IPO shift of the mid-1970s. They concluded that in fact statistically significant changes in these fields could be attributed to the phase shift of the IPO. At the same time, Dong and Dai (2015) found that models included in the CMIP3 and CMIP5 experiments are accurate in their representation of IPOrelated climate variability in the Pacific basin, which could result in a promising tool for near- and long-term climate predictions over the region.

The objective of this study is to characterize the main modes of SST variability in the SP region restricting the area of analysis to subtropical and extratropical latitudes from $20^{\circ} \mathrm{S}$ to $65^{\circ} \mathrm{S}$ by means of observational SST data. The choice of this latitude band is to avoid direct effects related to ENSO within the tropical band and also others related to sea ice, which are important during the cold season poleward of about $65^{\circ} \mathrm{S}$. Of particular interest is the identification of periodicities at interannual and longer time scales which could be a promising source for interannual-to-decadal climate prediction studies and also their links to ENSO- and IPO-driven variability as reported in previous works (Power et al. 1999; Power et al. 2006). The sections of this paper are as follows: Section 2 describes the SST data as well as the statistical methodology used in the paper. Section 3 includes the characterization of the modes of interannual SST variability, their periodicities and trends, as well as the impact of SP SST variability on changes in temperature and precipitation 
within the Southern Hemisphere. Finally, Section 4 consists of a discussion of results and the concluding remarks.

\section{Data and methods}

SST data comprises monthly mean values taken from version 1.1 of the HadISST dataset

122

123 (Rayner et al. 2003) which has a horizontal resolution of $1^{\circ} \times 1^{\circ}$ and includes in-situ measurements from the Met Office Marine Data Bank as well as satellite-derived SST information starting in 1982. It is important to stress that before 1982 there is a noticeable lack of measurements over this basin; therefore, the period of analysis runs from January 1982 to December 2015 (34 years). This study uses annual mean values of SST, so the original monthly values were averaged to derive 34 values (one per year) for every grid point. Unless stated otherwise, trends throughout the paper were computed as the slope of the linear regression of SST anomalies onto the global mean temperature following the technique of van Oldenborgh et al. (2009). The Mann-Kendall test (Mann 1945; Kendall 1955) was used to assess significance of the trends considering a confidence level of $5 \%$.

The statistical methods used to identify the main modes of variability of annual SST anomalies include Empirical Orthogonal Functions (EOF) as well as Complex EOF (CEOF; Wallace and Dickinson 1972; Horel 1984; Venegas et al. 1998). The CEOF technique is useful to study periodicities in modes of variability: it decomposes the variability into real and imaginary spatial maps which are amplified by real and imaginary time-varying coefficients (White and Annis 2004) which, taken together, characterize the main modes of variability in the original spatiotemporal dataset as a function of the phase in periodic spatial coefficients and periodic temporal scores (Ballester et al. 2011). This 
statistical tool is particularly suitable when propagation is evident in the observed features

141 (in this case, SST anomalies).

142

The potential relationships between variability in SST and in the atmosphere were analyzed by means of correlation analysis between the time series of the leading modes of SST variability in the SP region and precipitation and temperature anomalies within the Southern Hemisphere. Precipitation data was obtained from the GPCC dataset (Schneider et al. 2014) with a horizontal resolution of $1^{\circ} \times 1^{\circ}$, while temperature data was taken from version 3 of the Global Historical Climatology Network (GHCN; Lawrimore et al. 2011) which resolution is $0.5^{\circ} \times 0.5^{\circ}$. The relationships between the observed modes of SST variability in the SP region and other known modes of climate variability were explored using the time series of the El Niño 3.4 (N3.4) and IPO indices for the whole period 19822015. The N3.4 index is here considered as a proxy of ENSO variability (e.g. Trenberth 1997). In all correlation significance tests, the effective degrees of freedom have been considered taking into account the autocorrelation of the corresponding time series (Wilks 2011).

The analysis on the partial attribution of the observed temperature trends towards the end of the paper was performed using data of annual mean 10-mts $u$ and $v$ wind components, SLP and 2-mts temperature from the $20^{\text {th }}$ Century Reanalysis (Compo et al. 2011) and the NCEP/NCAR Reanalysis I (Kalnay et al. 1996).

\section{SST variability in the SP region}

Fig.1 shows the annual mean SST field derived from HadISST along with the observed trend for the whole period of analysis, 1982-2012. The mean field is characterized by a 
north-south gradient along with relatively cooler waters near the western coast of South America related to upwelling. The intensity of the meridional gradient increased along the period of analysis as can be inferred from the trends: positive north of about $40^{\circ} \mathrm{S}$ and null or negative south of $50^{\circ} \mathrm{S}$. The largest positive trends are found east of Australia and east of New Zealand, covering much of the subtropical western SP region. These and the negative trends around $55-60^{\circ} \mathrm{S}$ are significant (5\% confidence) according to the Mann-Kendall test. Overall, this trend pattern looks very similar to that derived by England et al. (2014) in spite of them using a shorter time period (1992-2011).

\section{a. EOF and CEOF analysis}

In the context of this study, EOFs represent the main modes of SST variability on interannual timescales. Fig. 2 shows the spatial structures of the leading modes of interannual SST variability as derived from the EOF analysis. The first mode (EOF1), which explains more than $39 \%$ of the variance, is related to a dipolar pattern with anomalies of opposite sign centered around $35^{\circ} \mathrm{S}, 160^{\circ} \mathrm{W}$ and $60^{\circ} \mathrm{S}, 130^{\circ} \mathrm{W}$ (usually called the South Pacific Ocean Dipole or simply SPOD; Huang and Shukla 2006) that covers from the central SP to the coasts of South America. This pattern is characterized by a horseshoe structure with positive (negative) anomalies located on subtropical regions of both the Northern (not shown) and Southern Hemispheres, and negative (positive) anomalies centered on the eastern tropical Pacific (e.g. Rasmusson and Carpenter 1982). Previous works found that this pattern is related to significant variability in the climate of the Southern Hemisphere, particularly over central and southern South America (e.g. Grimm et al. 2000; Da Silva et al. 2011) and in areas as far as Antarctica, where the sea ice concentration and cover are affected (Stammerjohn et al. 2008). It is worth noting that here 
the EOF analysis is applied to the original data (i.e. without removing the trends), which allows for the inspection of trends in these modes. In fact, the principal component (PC) associated with this EOF (Fig. 2d) depicts interannual variability with a positive and significant trend along the period of analysis.

Besides EOF1, when EOF2 and EOF3 are considered together more than $22 \%$ of the variability is added. Fig. 2b-c and 2e-f show the second and third leading EOFs and their associated PCs, respectively. As opposed to the horseshoe structure of EOF1, EOF2 and EOF3 are characterized by SST anomalies placed along the midlatitudes. It is interesting to note that the North test (North et al. 1982) indicates that both EOFs are not clearly separated in terms of variance, suggesting that both could actually be part of a single mode of variability. Regardless, the PC associated with EOF2 shows a positive and significant trend while the weak negative trend affecting EOF3 is not significant. The nature of this pair of EOFs is explored later via the CEOF analysis.

Table 1 lists the correlation coefficients computed between the time series of the three EOFs and the time series of N3.4 and IPO. The time series of PC1 is highly correlated with both ENSO and the IPO (significance exceeding 1\%), while that related to PC2 is only correlated with the IPO but in this case confidence does not exceed 5\%. Correlations derived for PC3 are low and not significant.

CEOF is here applied to look for potential propagation of the SST anomaly features. Fig. 3 shows the first mode resulting from the CEOF analysis applied to unfiltered SST data (CEOF1). The structures at phases $0^{\circ}$ and $180^{\circ}$ (which, by definition, are the same but with opposite sign) clearly depict the patterns associated with La Niña and El Niño, respectively, much like EOF1. However, this methodology also allows detecting how these anomalies evolve between El Niño/La Niña events, which becomes clear when CEOF1 is taken at 
intermediate times. For instance, during the dissipation stage of El Niño and La Niña events the horseshoe structure typical of ENSO weakens and the SPOD pattern also becomes much less marked. The magnitude of the SST anomalies tend to maximize close to $45^{\circ} \mathrm{S}$, $150^{\circ} \mathrm{W}$ and over the eastern coasts of Australia, followed by weakening and propagation towards the southeast. The amount of variance explained by this mode is $43.6 \%$.

In order to identify any differences in the modes of propagation as a function of the frequency of the SST variability, spectral analysis was applied to the time series of SST at every grid point. Fig. 4 depicts those grid points whose spectral power exceeds the level of $10 \%$ significance against the null hypothesis of white noise. The largest amount of points with significant spectral peaks was found for frequencies of 4 and 7 years (Fig. 4c and 4d with a total of 1083 and 2079 points, respectively). Consequently, the time series of SST anomalies at every grid point was time-filtered using 4- and 7-yr moving-averages and the CEOF technique was applied to these new time series thereafter.

Interestingly, if the CEOF analysis is performed on 4-yr and 7-yr filtered SST time series, results differ dramatically in terms of the propagation of the anomalies. Fig. 5 and 6 show the spatial patterns of CEOF1 using 4-yr and 7-yr filtered SST values, respectively. As expected, the time filtering of SSTs also filters out most of the high frequency related to ENSO and thus increases the fraction of variance explained now (53.3\% and 59.3\% for 4and 7-yr filtered time series, respectively). The most striking result, though, lies in the comparison of the structures: for the 4-yr filter, the patterns are very similar to those of the unfiltered series (Fig. 3) except for weaker anomalies overall. They look similar to those related to the $7-\mathrm{yr}$ filter but only at phases $135^{\circ}$ and $180^{\circ}$, as for the rest of the phases in the 7-yr filtered time series propagation is not visible. In fact, anomalies there show a pulsing dipolar SST pattern between midlatitudes and high latitudes of the SP around $180-150^{\circ} \mathrm{W}$. 
This is confirmed in Fig. 7 by plotting the temporal evolution of the temporal phases of CEOF1 for unfiltered (Fig. 7a), 4-yr filtered (Fig. 7b) and 7-yr filtered (Fig. 7c) SST time series. In the case of the unfiltered anomalies, clear propagation is visible between 1985 and 1989 and between 1996 and 1999, both coinciding with strong ENSO variability and migrations from El Niño to La Niña conditions. For 4-yr filtered values (Fig. 7b) there is still some propagation but only around 1990. However, when the 7-yr filtered values are considered (Fig. 7c) it is found that the propagation of the anomalies vanishes and only two states exist: that at phase $180^{\circ}$ (negative anomalies east of New Zealand, positive anomalies at higher latitudes; Fig. 5e) and the opposite one at phase $0^{\circ}$ (Fig. 6a).

The structures of the second mode of CEOF (CEOF2) for unfiltered SST anomalies are displayed in Fig. 8. This mode explains less than $17 \%$ of the variance and is mostly confined to midlatitudes, showing a west-east propagation of the anomalies within the South Pacific Gyre. It is interesting to note that part of these anomalies reach the SP region from the Indian Ocean (this becomes clear at phase $45^{\circ}$ ). Overall, similar results are obtained for 4- and 7-yr filtered SST anomalies (Fig. 9 and Fig. 10, respectively), although differences become noticeable when the temporal evolution of the phase is analyzed (Fig. 11). In this case propagation exists using unfiltered and filtered SST data, but the most clear pattern is discernable for 4-yr filtering (Fig. 11b) and 7-yr filtering (Fig. 11c), in which a slow propagation of the SST anomalies is found. This slow mode takes more than 10 years to complete a full phase cycle, with a maximum of 15 years (between 1996 and 2010) for the 7-yr-filter case.

Fig. 11 shows the spatial correlations computed on the spatial fields of CEOF1 and CEOF2 at different phases against the three EOFs patterns displayed in Fig. 2a-c. For CEOF1, correlations are very high when compared to EOF1 at phase $0^{\circ}$ but then drop dramatically, 
mostly in line with the tight linkage between this mode and ENSO (Table 1). Much lower correlation coefficients are attained when comparing against EOF2, but once again values increase for EOF3, in particular at CEOF1 phases $45^{\circ}, 90^{\circ}$ and $135^{\circ}$.

When correlations with the second leading mode of the CEOF analysis are considered (CEOF2; Fig. 12b), the only statistically significant correlation coefficients (5\% confidence) are obtained for EOF2. This seems consistent with the zonal propagation of SST anomalies within the South Pacific Gyre that were discussed previously and that are present in both EOF2 and CEOF2. It is interesting to note that similar conclusions were obtained by Ballester et al. (2011) in a paper in which they only considered the region south of $50^{\circ} \mathrm{S}$.

b. Relationship of SP variability with temperature and precipitation trends and anomalies in the Southern Hemisphere

Correlation coefficients computed on the EOF time series against grid-point temperature and precipitation anomalies are shown in Figs. 13 and 14, respectively. In the case of EOF1 (which as was discussed above is linked to ENSO variability) the correlation patterns of temperature and precipitation anomalies are consistent with those associated with ENSO: during La Niña (El Niño) years, warmer (colder) conditions prevail over northern South America, southeastern Brazil and also over parts of New Zealand, while colder (warmer) temperatures prevail over northern Australia and most of the Pacific coasts of South America (Fig. 13a). For rainfall (Fig. 14a), under La Niña (El Niño) more (less) rain falls over northern Australia and northern South America, and drier (wetter) conditions prevail over southern Brazil, northern Argentina and Uruguay. 
Regarding correlation against EOF2 and EOF3, EOF2 variability relates to distinct temperature patterns over most of South America and parts of South Africa (Fig. 13b), while EOF3 has much weaker (not significant) signal over the same areas and also over southern Australia (Fig. 13c). In the case of precipitation, correlation coefficients are overall smaller than in the case of temperature but nonetheless positive and significant over southeastern South America and negative and significant over northern South America and central Africa for EOF2 (Fig. 14b), as well as negative and significant over a small region in central Australia for EOF3 (Fig. 14c).

The relationship between the leading modes of SST variability in the SP region and temperature and precipitation anomalies discussed above begs the question of whether the long-term trends observed in the EOFs (Fig. 2d-f) could be linked to those in selected atmospheric variables. To investigate this issue, Fig. 15 displays the observed trends (computed as the slope of the least-squares fit; period 1982-2015) in temperature and precipitation across the Southern Hemisphere. Regarding temperature (Fig. 15a), most of the continental regions of the Southern Hemisphere have warmed significantly (5\% level) over most of central-northern South America, subtropical Africa and southern Australia. Some cooling has taken place at the same time over central-western South America (particularly the Andean region of Bolivia and Peru) and also over parts of the North Island of New Zealand, but these signals are not significant. Meanwhile, precipitation trends (Fig. 15b) are much less homogeneous, although rainfall increased significantly over northern Australia and Indonesia and decreased at subtropical latitudes of central Africa and central South America east of the Andes.

In order to partially explain the observed changes in temperature and precipitation, Fig. 16 shows the regression coefficients of SLP and temperature advection (TADV) anomalies 
(computed respect to their long-term annual means) from the $20^{\text {th }}$ Century Reanalysis upon the time series of the three EOFs. Fig. 16a displays the pattern associated with EOF1. Regarding SLP, this pattern is related to higher surface pressures in the subtropical SP centered near $40^{\circ} \mathrm{S}$ and a negative SLP anomaly further south that affects southern Chile and Argentina as well as much of the Antarctic Peninsula (not shown). Recently, Clem and Fogt (2015) concluded that the strengthening of the cyclonic conditions over that area was driven by the change in IPO conditions towards its negative phase since the 1990s. Further west, slightly lower-than-average SLPs affect northern Australia and enhanced anticyclonic conditions are found south of South Africa. Naturally, these SLP pattern variations (and their associated changes in surface winds) also drive modifications in low-level TADV. For instance, the deepening of the southern SP low close to the Antarctic Peninsula leads to enhanced warm advection over the SP waters off the southern coasts of Chile, while the intensification of the subtropical SP high pressure system provides warm advection to much of the Polynesia and, to a lesser extent, to northern New Zealand, which is in fact found in the regression field of TADV. For EOF2 and EOF3 (Fig. 16b,c), cyclonic anomalies are weaker than in the case of EOF1 and slightly displaced to the east. Also, the anticyclonic anomaly appears shifted westwards of (and much weaker than) its EOF1related position.

Combining results from the EOF interannual variability analysis (Fig. 2) and those discussed above, it can be seen that the observed positive trend in EOF1 and EOF2 could have contributed to the strengthening of the positive TADV close to the Antarctic Peninsula and far southern Chile. Furthermore, the positive trends in EOF1 and in EOF2 might be partly responsible for the cooling detected over northern Australia and subtropical Africa, respectively (Fig. 15a). It is worth noting that this reasoning should be taken as a "partial 
attribution" statement. There are obviously other features of the atmospheric variability that might have also affected temperature and precipitation in the region under analysis and that are not being taken into account here. For instance, the large and significant warming trend observed over northern Brazil (Fig. 15a) cannot be explained solely by variability in the SP basin, so other players must have been acting there. It is also important to mention that very similar results were derived using NCEP/NCAR Reanalysis I, except for the field related to EOF3 in which the cyclonic anomaly in the southeast Pacific is found about $1000 \mathrm{~km}$ west compared to the $20^{\text {th }}$ Century dataset (not shown).

\section{Discussion and conclusions}

This paper identified the main modes of interannual SST variability in the SP region using in situ observations during the period 1982-2015. The region has experienced a noticeable warming over subtropical latitudes and a gradual cooling towards higher latitudes. The leading mode of SST variability is associated with ENSO and IPO and displays a horseshoe structure of SST anomalies covering much of the subtropical SP. Anomalies of one sign cover the coasts of South America and most of the midlatitudes and anomalies of opposite sign are found east of Australia and New Zealand, accounting for almost $40 \%$ of the variance. EOF2 and EOF3, on the other hand, are associated with travelling SST anomalies that propagate along midlatitudes across the SP basin. These propagating SST anomalies are also in part tropically driven since they are partly triggered by convective activity over Australia and the Western Pacific as suggested by Guan et al. (2014) and propagate within the southern South Pacific Gyre, travelling all the way from Australia towards South America. Renwick and Revell (1999) found that a similar mechanism but in the atmosphere 
explains the propagation of pressure anomalies from the tropical Pacific onto midlatitudes, helping in the formation of atmospheric blocking in the southeastern SP area.

EOF1 has experienced a positive trend along the period of analysis, mostly in line with the IPO phase change (e.g. England et al. 2014), and this has as well increased the frequency of La Niña-like conditions over the SP basin. Trends for EOF2 (which is also related to IPO) were also positive, while EOF3 had a weak and not significant negative trend.

In summary, SST variability in the SP region is dominated by an extra-tropical mode of anomalies propagating inside the sub-tropical gyre plus another mode forced by tropical variability (ENSO and IPO). This was confirmed by CEOF analysis calculated on observed SST anomalies: the leading mode of variability (CEOF1) was significantly correlated to ENSO and, taken at different phases, showed the evolution of El Niño to La Niña conditions over the SP region. The evolution of such anomalies was made clear when unfiltered SST anomalies were used, as time filtering of the anomalies indicated that no propagation was found at low (i.e. 7-yr filtered) frequencies. As of CEOF2, the pattern was related to SST anomalies propagating through midlatitudes and in this case the propagation was most clear when the low frequency variability only was considered, suggesting a tight link with the slow IPO-related variability. Still, it should be noted here that although the way in which SST anomalies propagate within midlatitudes is primarily from the coasts of New Zealand towards South America, there are periods (e.g. between 2000 and 2005) when anomalies propagated in the opposite direction as noted in previous works (e.g. Qiu and Chen 2006; Sasaki et al. 2008). Roemmich et al. (2016) argue that part of this change may be due to the increase in the anticlockwise circulation within the SP basin that has been taking place there for the last two decades. 
Correlation analysis indicated that EOF1 is linked to patterns of significant temperature and rainfall anomalies over continental regions of the Southern Hemisphere. In fact, most of the signals are consistent with those associated with the different phases of ENSO, which is something reasonable given the link existing between EOF1 and ENSO. However, results also showed distinct anomaly patterns for EOF2 and EOF3. In particular, EOF3 related to cooler (but not significant) conditions over much of South America and southern Africa as well as over some parts of western Australia. EOF2, in turn, was positively correlated with temperature anomalies over most of central-northern South America as well as southern Australia.

The analysis of the patterns of SLP and TADV anomalies under strong phases of the EOFs suggested that part of the surface warming that occurred over the continental regions of the Southern Hemisphere may have been related to the positive trends in the IPO-related EOF1 and EOF2 patterns. Undoubtedly, there have also been other mechanisms associated with circulation changes over the Southern Hemisphere which explain observed changes in temperature, but SP variability has had at least some contribution.

\section{Acknowledgments}

The authors would like to thank Scott Power for his comments on an earlier version of the manuscript and the two anonymous reviewers whose suggestions led to a substantial improvement of the paper. This study was supported by Grants UBACyT20020100100803, UBACyT-20020120300051, PIP-11220120100586 and the SPECS (GA 308378) EU-funded Project. JG-S was partially supported by the H2020-funded MSCA-IFEF DPETNA project (GA No. 655339). The authors acknowledge the Red Española de Supercomputación (RES) and PRACE for awarding access to MareNostrum 3 at the 
403 Barcelona Supercomputing Center through the HiResClim project. The support of Virginie 404 Guémas and Oriol Mula-Valls at the Barcelona Supercomputing Center is warmly 405 appreciated.

406 


\section{References}

Ballester J, Rodríguez-Arias MA, Rodó X (2011) A new extratropical tracer describing the role of the Western Pacific in the onset of El Niño: implications for ENSO understanding and forecasting. J Climate 24:1425-1437.

Barros VR, Silvestri GE (2002) The relation between sea surface temperature at the subtropical south-central Pacific and precipitation in southeastern South America. J Climate 15:251-267.

Clem KR, Fogt RL (2015) South Pacific circulation changes and their connection to the tropics and regional Antarctic warming in austral spring, 1979-2012. J Geophys Res 120(7):2773-2792.

Compo GP, Whitaker JS, Sardeshmukh PD, Matsui N, and Coauthors (2011) The Twentieth Century Reanalysis Project. Quarterly J Roy Meteor Soc 137:1-28.

Da Silva GAM, Drumond A, Ambrizzi T (2011) The impact of El Niño on South American summer climate during different phases of the Pacific Decadal Oscillation. Theor Appl Climatol 106:307-319.

Dong B, Dai A (2015) The influence of the Interdecadal Pacific Oscillation on temperature and precipitation over the globe. Clim Dyn 45:2667-2681.

England MH, McGregor S, Spence P, Meehl GA, Timmermann A, Cai W, Sen Gupta A, McPhaden MJ, Purich A, Santoso A (2014) Recent intensification of wind-driven circulation in the Pacific and the ongoing warming hiatus. Nature Clim Change, 4:222227.

Gershunou A, Barnett TP, Cayan DR (1999) North Pacific interdecadal oscillation seen as factor in ENSO-related North American climate anomalies. Eos 80: 25-30. 
Grimm AM, Barros VR, Doyle ME (2000) Climate variability in southern South America associated with El Niño and La Niña events. J Climate 13:35-58.

Guan Y, Zhu J, Huang B, Hu ZZ, Kinter III JL (2014) South Pacific Ocean Dipole: A predictable mode on multiseasonal time scales. J Climate 27:1648-1658.

Horel JD (1984) Complex Empirical Component Analysis: theory and examples. J Clim Appl Meteorol 23:1660-1673.

Huang B, Shukla J (2006) Interannual SST variability in the southern subtropical and extratropical ocean. Tech Rep 223, Center for Ocean-Land-Atmosphere Studies, Calverton, $\mathrm{MD}, 20 \mathrm{pp}$.

Hurwitz MM, Newman PA, Garfinkel CI (2012) On the influence of North Pacific sea surface temperature on the Arctic winter climate. J Geophys Res Atmospheres 117: D19110.

Jacques-Copper M, Garreaud RD (2015) Characterization of the 1970s climate shift in South America. Int J Climatol 35:2164-2179.

Kalnay E and coauthors (1996) The NCEP/NCAR 40-year reanalysis project. Bull Am Meteorol Soc 77:437-471.

Karoly DJ, Plumb RA, Ting M (1989) Examples of the horizontal propagation of quasistationary waves. J Atmos Sci 46: 2802-2811.

Kendall M (1955) Rank Correlation Methods, $5^{\text {th }}$ edn. M Kendall and J Gibbons (Eds.), New York, Oxford University Press, 260 pp.

Kidson JW, Renwick JA (2002) The Southern Hemisphere evolution of ENSO during 1981-1999. J Climate 15:847-863.

Latif M, Barnett TP (1994) Causes of decadal climate variability over the North Pacific and North America. Science, 266, 634-637. 
Lawrimore JH, Menne MJ, Gleason BE, Williams CN, Wuertz DB, Vose RS, Rennie J (2011) An overview of the Global Historical Climatology Network monthly mean temperature data set, version 3. J Geophys Res D: Atmospheres 116:1-18.

Lienert F, Doblas-Reyes FJ (2013) Decadal prediction of interannual tropical and North Pacific sea surface temperature. J Geophys Res Atmospheres 118: 5913-5922.

Linsley BK, Wellington GM, Schrag DP, Ren L, Salinger MJ, Tudhope AW (2000) Geochemical evidence from corals for changes in the amplitude and spatial pattern of South Pacific interdecadal climate variability over the last 300 years. Clim Dyn 22:111.

Mann H (1945) Nonparametric tests against trends. Econometrica 13:245-259.

Montecinos A, Pizarro O (2005) Interdecadal SST-SLP coupled variability in the South Pacific. J Geophys Res 110. doi: 10.1029/2004JC002743.

Morioka Y., Ratnam J. V., Sasaki W., Masumoto Y., 2013: Generation mechanism of the South Pacific Subtropical Dipole. J. Climate, 26, 6033-6045.

North GR, Bell TL, Cahalan RF, Moeng FJ (1982) Sampling errors in the estimation of empirical orthogonal functions. Mon Wea Rev 110:699-706.

Peterson RG, White WB (1998) Slow oceanic teleconnections linking the Antarctic Circumpolar Wave with the tropical El Niño-Southern Oscillation. J Geophys Res 103:24573-24583.

Power S, Casey T, Folland C, Colman A, Mehta V (1999) Inter-decadal modulation of the impact of ENSO on Australia. Clim Dyn 15:319-324.

Power S, Haylock M, Colman R, Wang X (2006) The predictability of interdecadal changes in ENSO activity and ENSO teleconnections. J Climate 19:4755-4771. 
Qiu B, Chen S (2006) Decadal variability in the large-scale sea surface height field of the South Pacific Ocean: observations and causes. J Phys Ocean 36:1751-1762.

Rasmusson EM, Carpenter TH (1982) Variations in tropical sea surface temperature and surface wind fields associated with the Southern Oscillation/El Niño. Mon Wea Rev 110:354-384.

Rayner NA, Parker DE, Horton EB, Folland CK, Alexander LV, Rowell DP, Kent EC, Kaplan A (2003) Global analyses of sea surface temperature, sea ice, and night marine air temperature since the late nineteenth century. J Geophys Res D: Atmospheres 108. doi: 10.1029/2002JD002670.

Renwick JA, Revell MJ (1999) Blocking over the South Pacific and Rossby wave propagation. Mon Wea Rev 127:2233-2247.

Roemmich D, Gilson J, Sutton P, Zilberman N (2016) Multidecadal change of the South Pacific Gyre circulation. J Phys Ocean 46:1871-1883.

Salinger MJ, Renwick JA, Mullan AB (2001) Interdecadal Pacific Oscillation and South Pacific climate. Int J Climatol 21:1705-1721.

Sasaki YN, Minobe S, Schneider N, Kagimoto T, Nonaka M, Sasaki H (2008) Decadal sea level variability in the South Pacific in a global eddy-resolving ocean model hindcast. J Phys Ocean 38:1731-1747.

Schneider U, Becker A, Finger P, Meyer-Christoffer A, Ziese M, Rudolf B (2014) GPCC's new land surface precipitation climatology based on quality-controlled in situ data and its role in quantifying the global water cycle. Theor Appl Climatol 115:15-40.

Shakun JD, Shaman J (2009) Tropical origins of North and South Pacific decadal variability. Geophys Res Lett 36 L19711. 
500

501

502

503

504

505

506

507

508

509

510

511

512

513

514

515

516

517

518

519

520

521

522

523

Stammerjohn SE, Martinson DG, Smith RC, Yuan X, Rind D (2008) Trends in Antarctic annual sea ice retreat and advance and their relation to ENSO and Southern Annular Mode variability. J Geophys Res. doi: 10.1029/2007JC004269.

Tatebe H, Imada Y, Mori M, Kimoto M, Hasumi H (2013) Control of decadal and bidecadal climate variability in the tropical Pacific by the off-equatorial South Pacific Ocean. J Climate 26:6524-6534.

Trenberth KE (1997) The definition of El Niño. Bull Am Meteorol Soc 78:2771-2777.

Van Oldenborgh GJ, te Raa LA, Dijkstra HA, Philip SY (2009) Frequency-amplitudedependence effect of the Atlantic meridional overturning on the tropical Pacific Ocean. Ocean Sci 5: 293-301.

Venegas SA, Mysak LA, Straub DN (1998) An interdecadal climate cycle in the South Atlantic and its links to other ocean basins. J Geophys Res 103:24723-24736.

Wallace JM, Dickinson RE (1972) Empirical orthogonal representation of time series in the frequency domain. Part I: Theoretical considerations. J Appl Meteor 11: 887-892.

White WB, Chen S-C, Allan RJ, Stone RC (2002) Positive feedbacks between the Antarctic Circumpolar Wave and the global El Niño-Southern Oscillation Wave. J Geophys Res 107 (C10), 3165, doi:10.1029/2000JC000581.

White WB, Annis J (2004) Influence of the Antarctic circumpolar wave on El Niño and its multidecadal changes from 1950 to 2011. J Geophys Res 109, C06019, doi:10.1029/2002JC001666.

White WB, Peterson RG (1996) An Antarctic circumpolar wave in surface pressure, wind, temperature and sea ice extent. Nature 380: 699-702.

Wilks D (2011) Statistical methods in the atmospheric sciences. Academic Press, Elsevier, The Netherlands. 

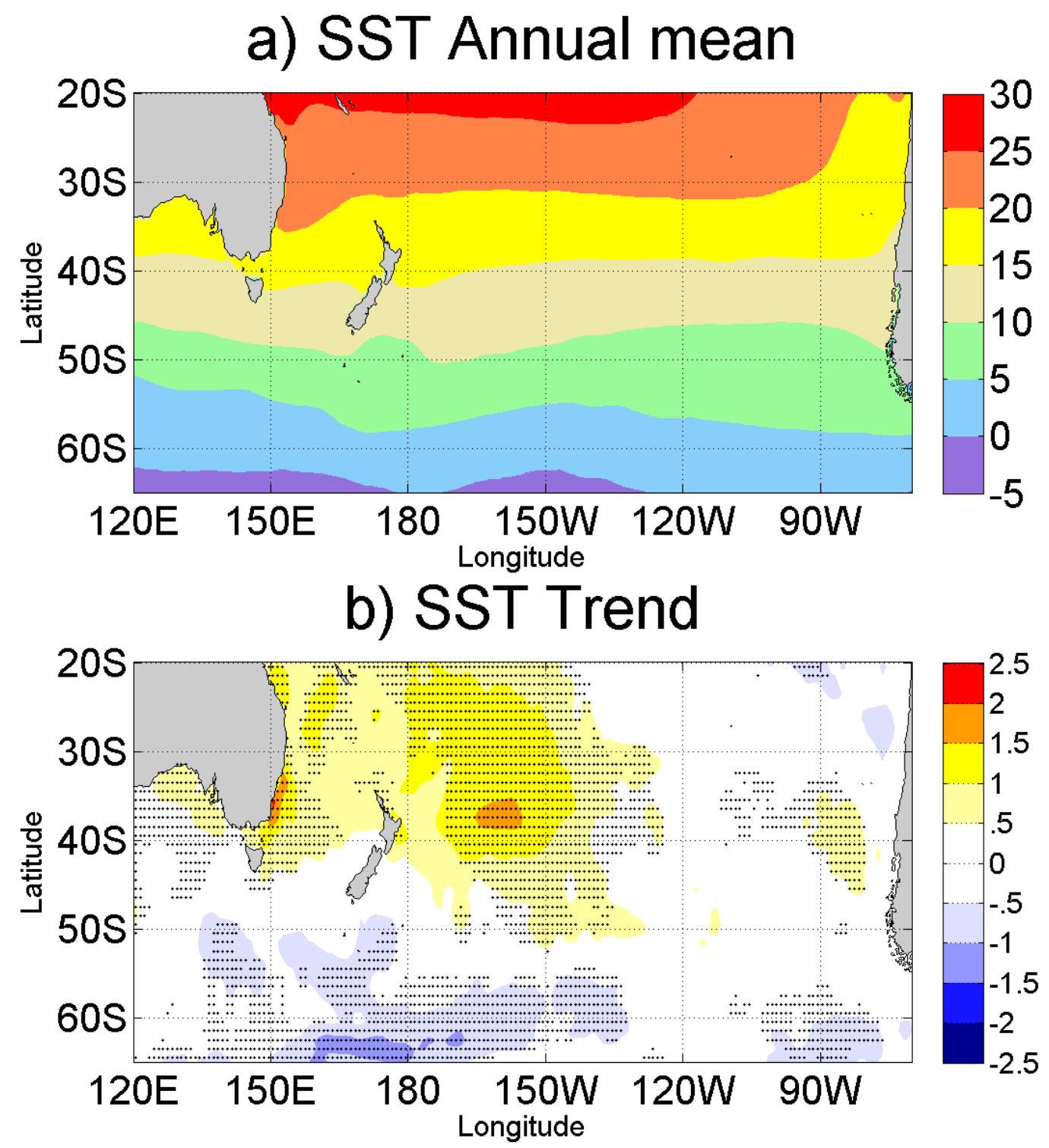

Fig. 1 (a) Annual mean SST (in ${ }^{\circ} \mathrm{C}$ ) and (b) trends in SST computed as the slope of the linear regression of SST anomalies onto the global mean temperature (in $\mathrm{K} \mathrm{K}^{-1}$ ) considering the whole period, 1982-2015. The black dots in $(b)$ denote those trends that are significant at the 5\% confidence level according to the Mann-Kendall test. 
a) EOF1 (39.2\%)

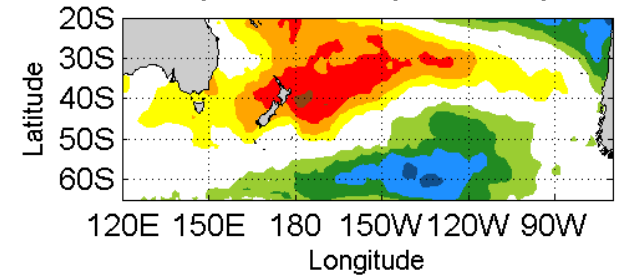

b) EOF2 (14.3\%)

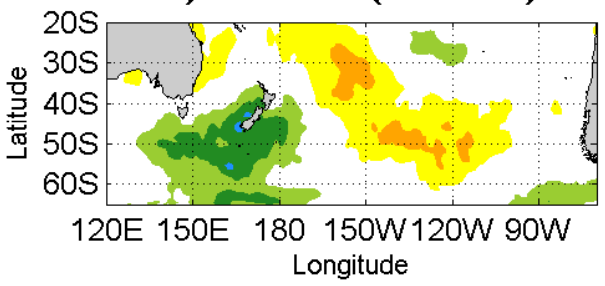

c) EOF3 (8.0\%)

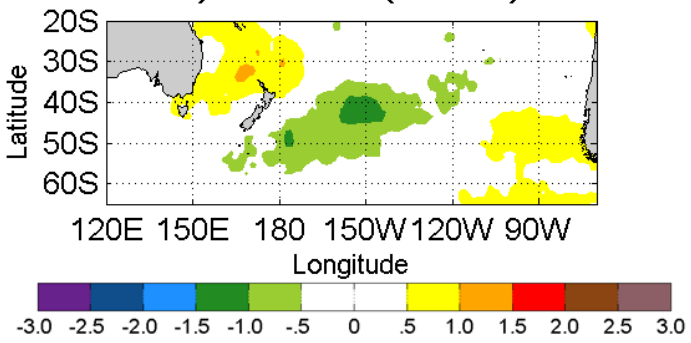

d) $\mathrm{PC} 1$

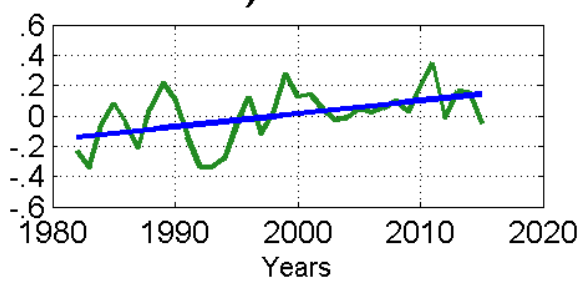

e) $\mathrm{PC} 2$

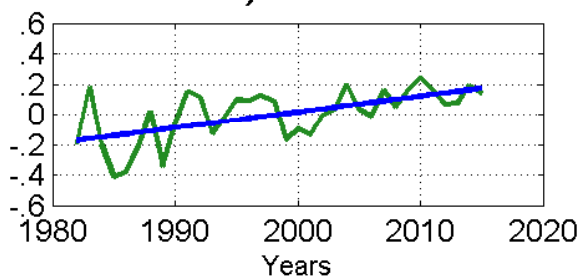

f) $\mathrm{PC} 3$

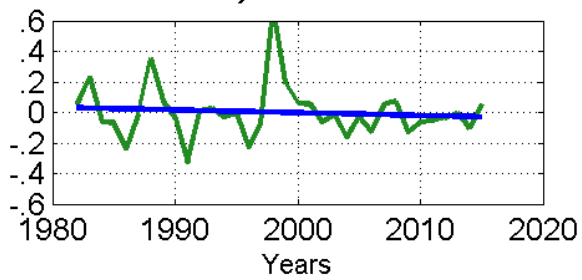

Fig. 2 Leading modes of interannual SST variability in the SP region. (a) First, (b) second $(c)$ and third EOF structures, with their associated normalized time series $(d, e$ and $f$, respectively). The blue lines in $(d),(e)$ and $(f)$ indicate the linear least-squares fitting (i.e. linear trends). Trends in PC1 and PC2 are significant at the 5\% confidence level while that in PC3 is not significantly different from zero according to a Mann-Kendall test. 


\section{CEOF1 unfiltered $(43.6 \%)$}

a) $\phi=0^{\circ}$

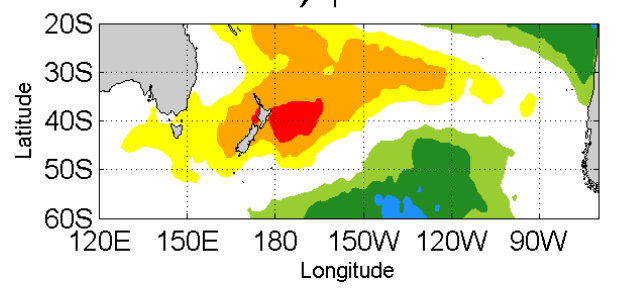

c) $\phi=90^{\circ}$

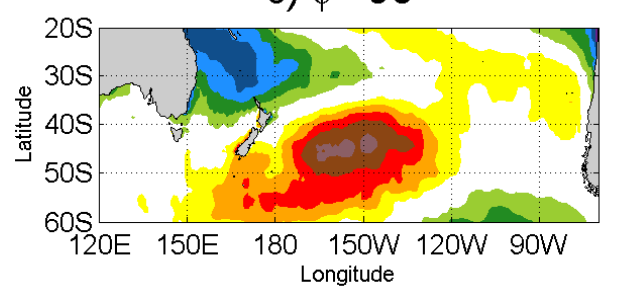

e) $\phi=180^{\circ}$

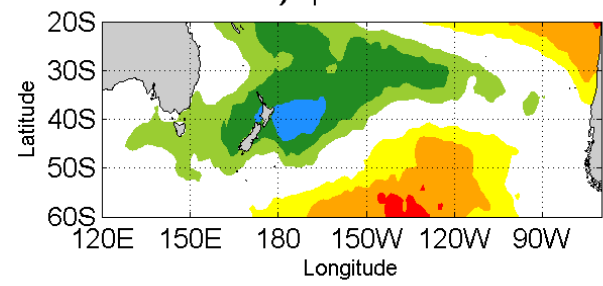

g) $\phi=270^{\circ}$

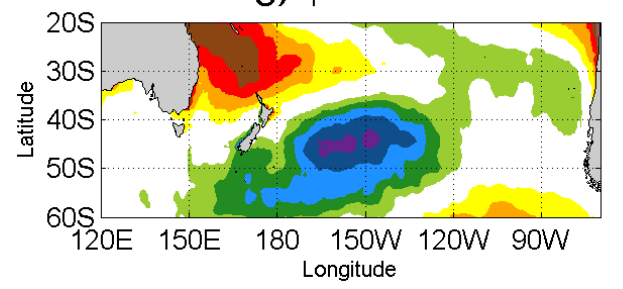

b) $\phi=45^{\circ}$

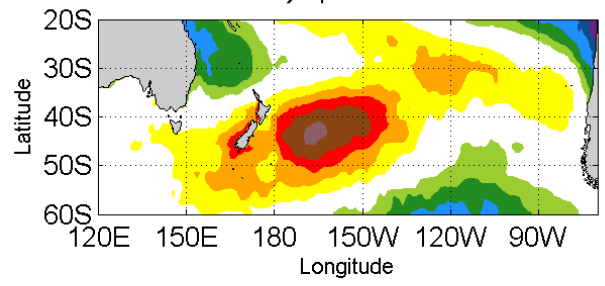

d) $\phi=135^{\circ}$

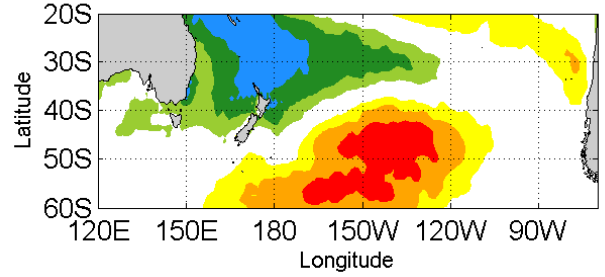

f) $\phi=225^{\circ}$

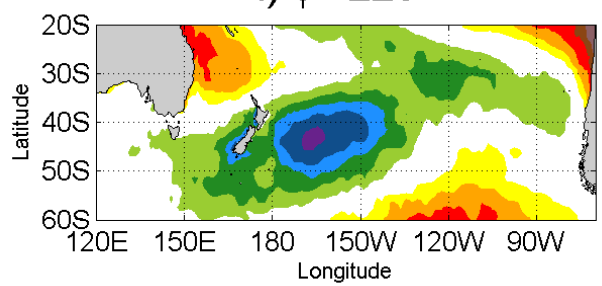

h) $\phi=315^{\circ}$

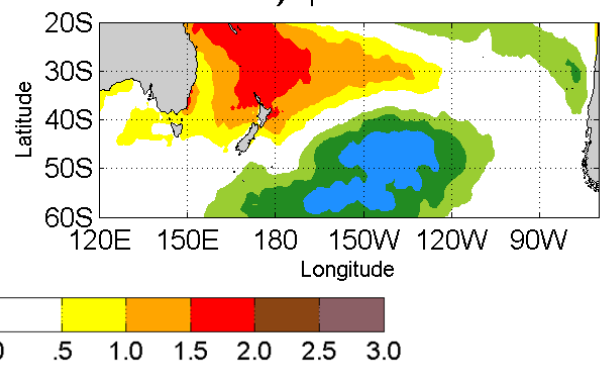

540

541

542

543

Fig. 3 CEOF analysis of annual mean SST anomalies. Spatial structures of CEOF1 (explained variance $=43.6 \%$ ) as a function of time phase $\phi$ from $(a) \phi=0^{\circ}$ to $(h) \phi=315^{\circ}$. 
a) Freq=1/20yrs

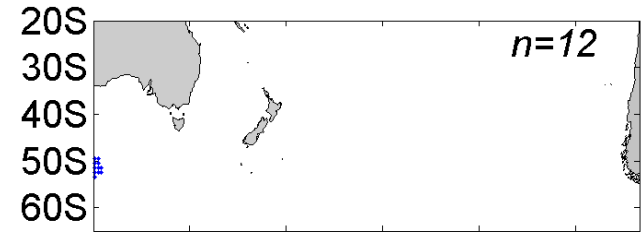

120E 150E 180 150W120W 90W

c) Freq $=1 / 7 \mathrm{yrs}$

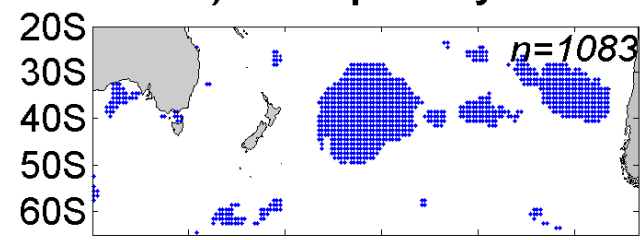

120E 150E 180 150W120W 90W

e) Freq=1/3.3yrs

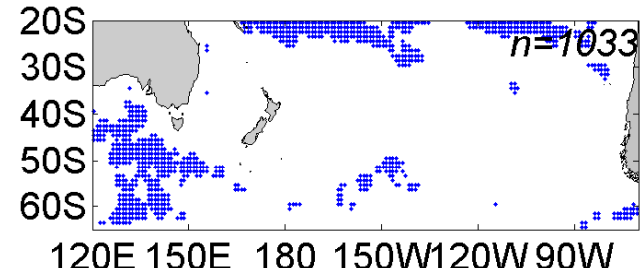

g) Freq=1/2.5yrs

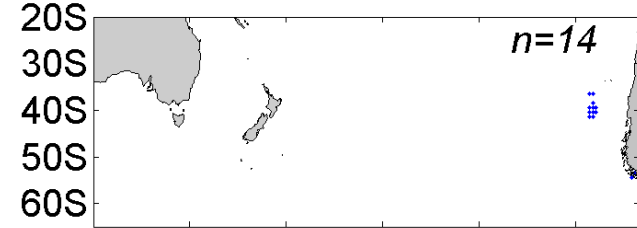

120E 150E 180 150W120W 90W b) Freq $=1 / 10 y r s$

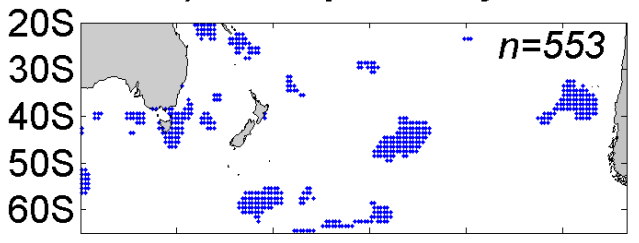

120E 150E 180 150W120W 90W

d) Freq $=1 / 4 \mathrm{yrs}$

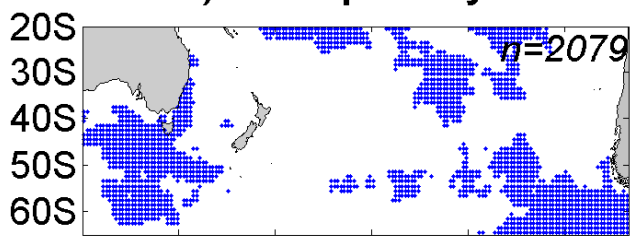

120E 150E 180 150W120W 90W

f) Freq=1/2.8yrs

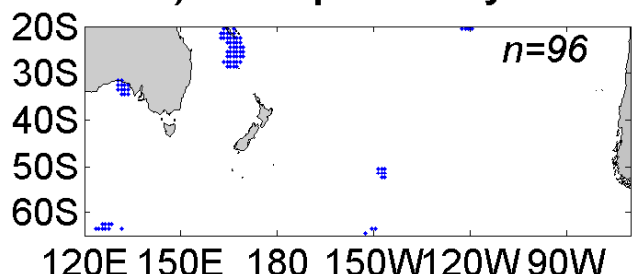

h) Freq $=1 / 2 \mathrm{yrs}$

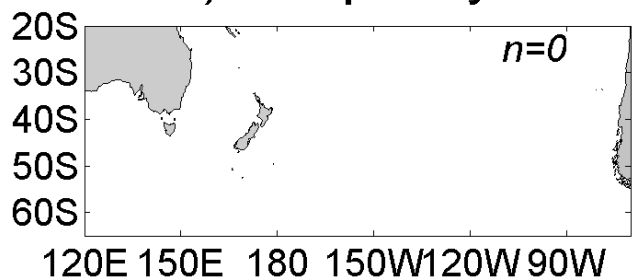

Fig. 4 Location of the grid points where spectral peaks at each given frequency exceed the $10 \%$ confidence level against the null hypothesis of white noise (blue dots), considering frequencies of (a) $1 / 20 \mathrm{yrs}^{-1}$; (b) $1 / 10 \mathrm{yrs}^{-1}$; (c) $1 / 7 \mathrm{yrs}^{-1}$; (d) $1 / 4 \mathrm{yrs}^{-1}$; (e) $1 / 3.3 \mathrm{yrs}^{-1}$; (f) $1 / 2.8 \mathrm{yrs}^{-1} ;(g) 1 / 2.5 \mathrm{yrs}^{-1}$; and $(h) 1 / 2 \mathrm{yrs}^{-1}$. The numbers in italic in the upper right corner of each subfigure indicate the total number of grid points with significant spectral peaks for that given frequency. 


\section{CEOF1 filt4yr (53.3\%)}

a) $\phi=0^{\circ}$

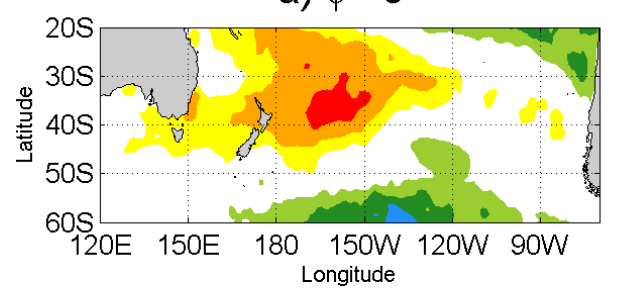

c) $\phi=90^{\circ}$

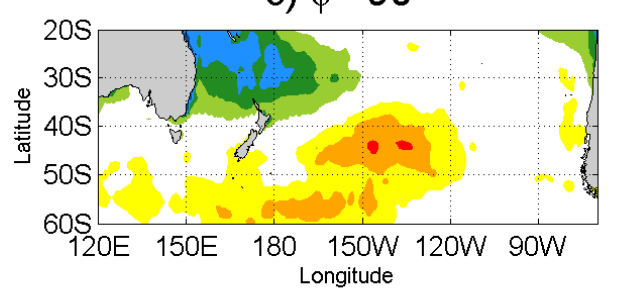

e) $\phi=180^{\circ}$

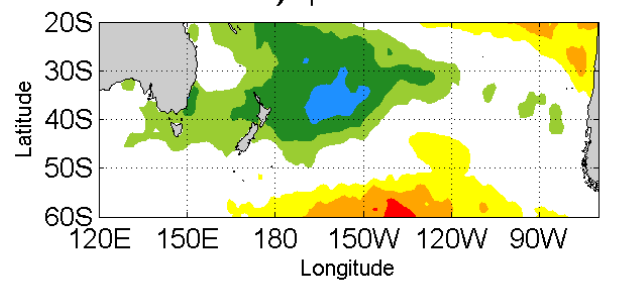

g) $\phi=270^{\circ}$

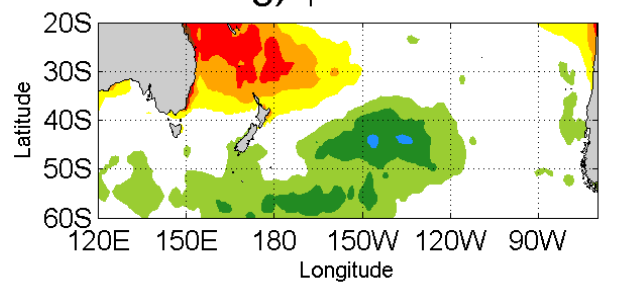

b) $\phi=45^{\circ}$

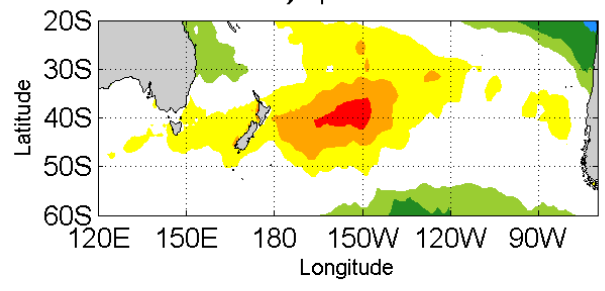

d) $\phi=135^{\circ}$

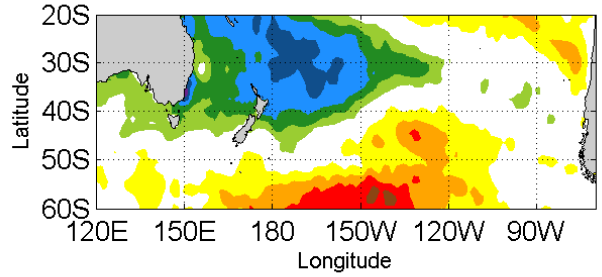

f) $\phi=225^{\circ}$

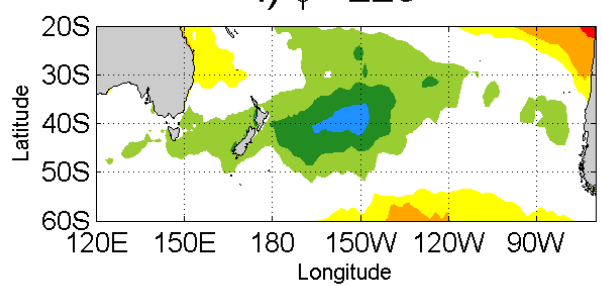

h) $\phi=315^{\circ}$

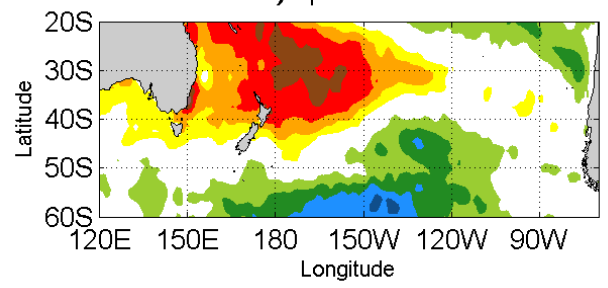

Fig. 5 As in Fig. 3 but using 4-yr filtered SST anomalies. The variance explained by this mode is $53.3 \%$. 


\section{CEOF1 filt7yr (59.3\%)}

a) $\phi=0^{\circ}$

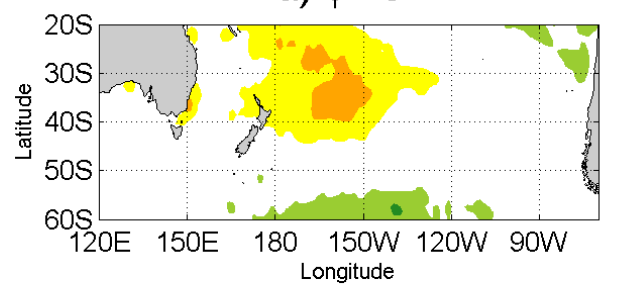

c) $\phi=90^{\circ}$

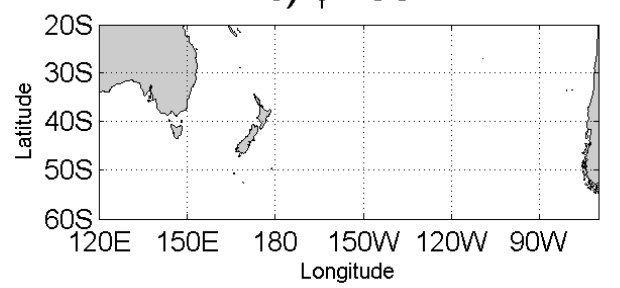

e) $\phi=180^{\circ}$

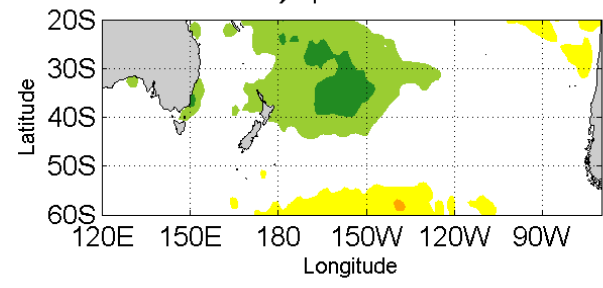

g) $\phi=270^{\circ}$

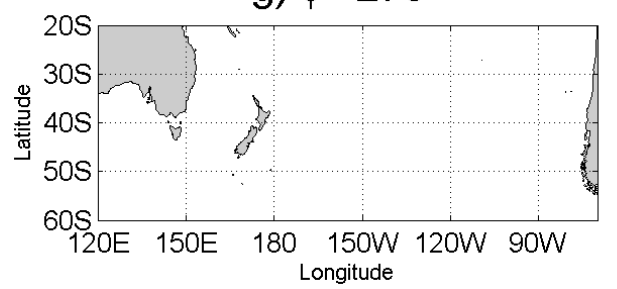

b) $\phi=45^{\circ}$

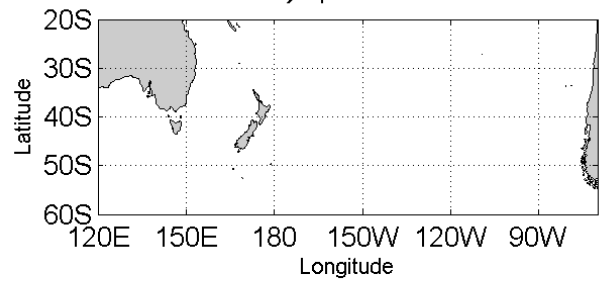

d) $\phi=135^{\circ}$

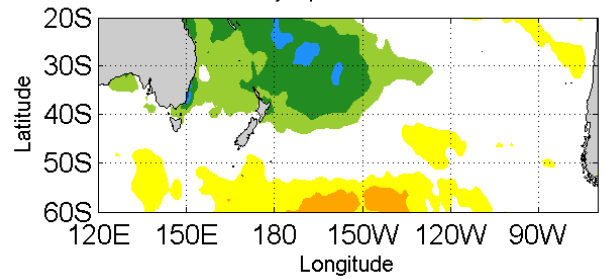

f) $\phi=225^{\circ}$

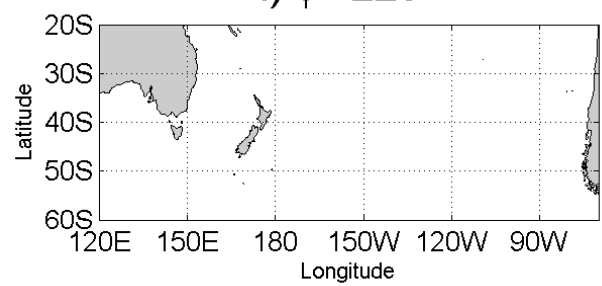

h) $\phi=315^{\circ}$

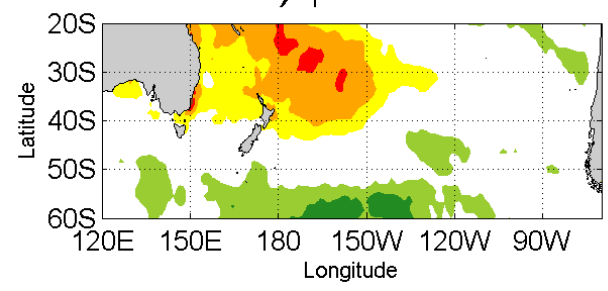

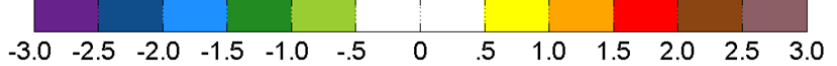

Fig. 6 As in Fig. 3 but using 7-yr filtered SST anomalies. The variance explained by this 
a) CEOF1 unfiltered

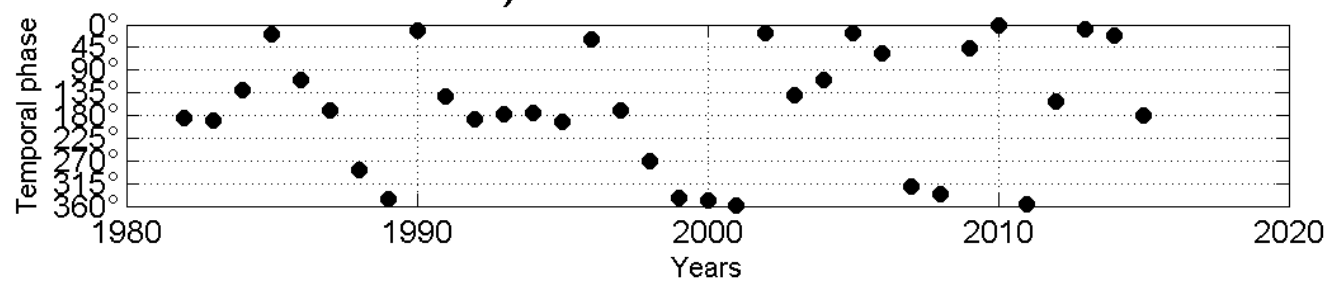

b) CEOF1 filt4yr

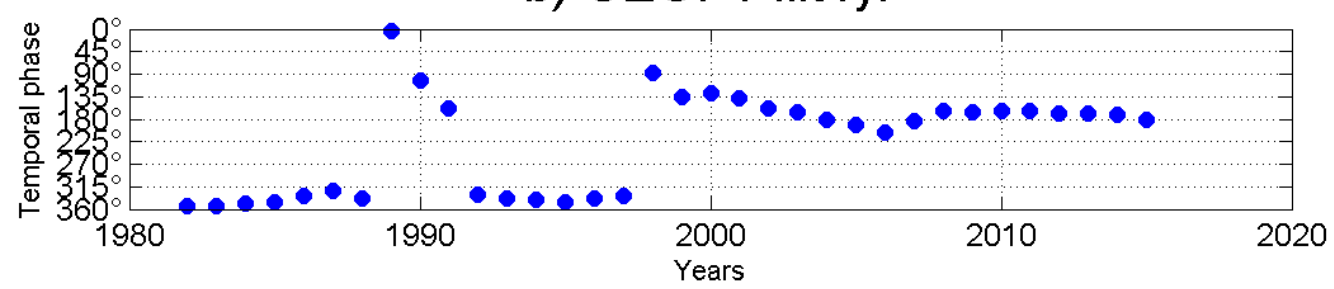

c) CEOF1 filt7yr

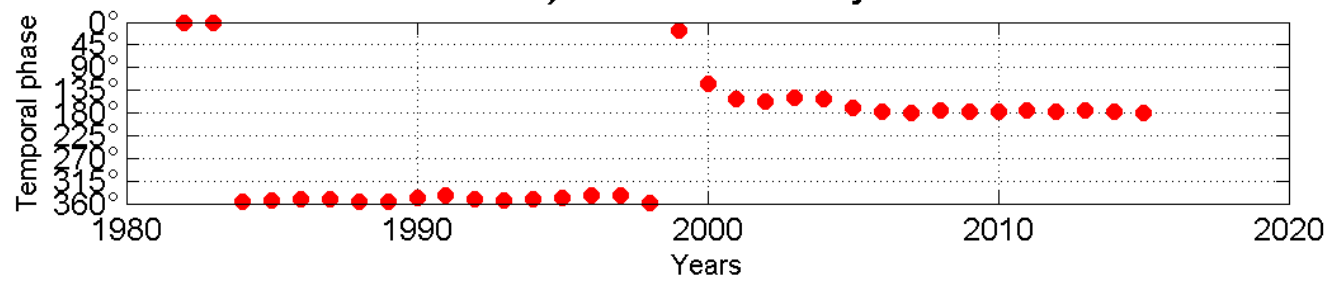

560

561 Fig. 7 Time evolution of the temporal phase associated with CEOF1 for $(a)$ unfiltered SST 562 anomalies; (b) 4-yr filtered SST anomalies; and (c) 7-yr filtered SST anomalies. The angles 563 of the phase are indicated in the y-axis. 


\section{CEOF2 unfiltered (16.8\%)}

a) $\phi=0^{\circ}$

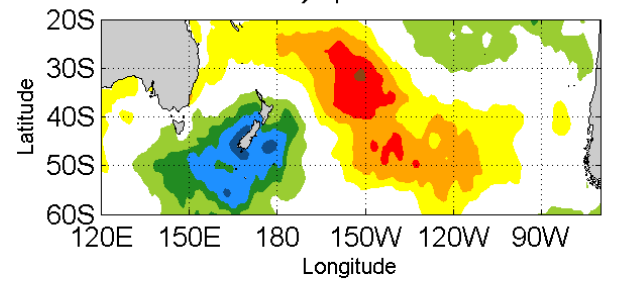

c) $\phi=90^{\circ}$

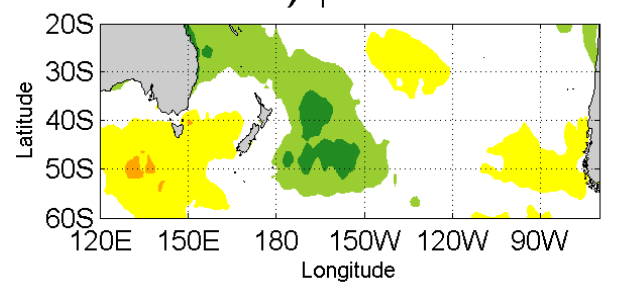

e) $\phi=180^{\circ}$

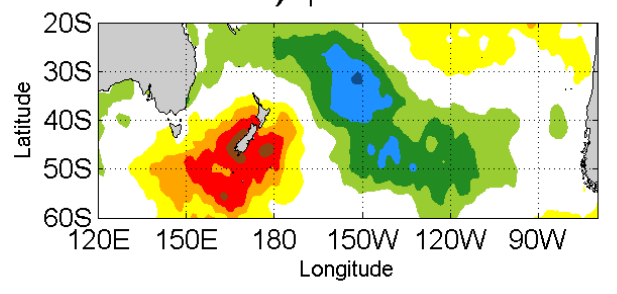

g) $\phi=270^{\circ}$

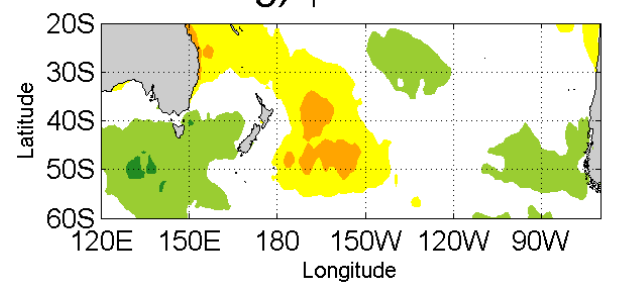

b) $\phi=45^{\circ}$

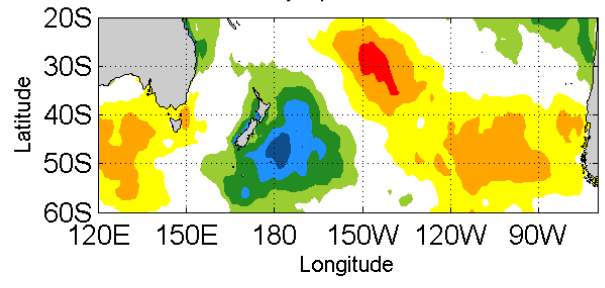

d) $\phi=135^{\circ}$

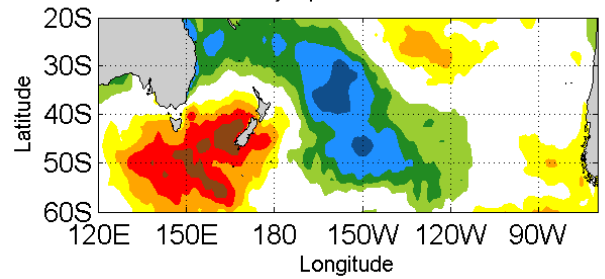

f) $\phi=225^{\circ}$

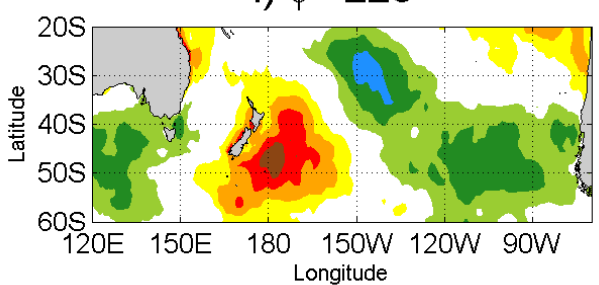

h) $\phi=315^{\circ}$

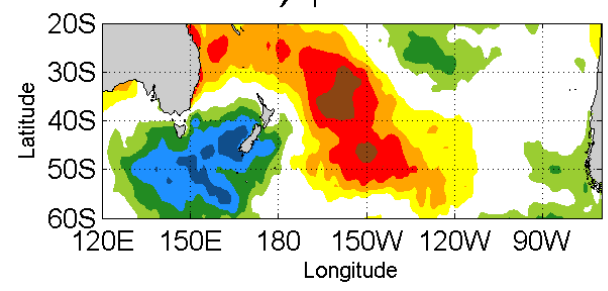

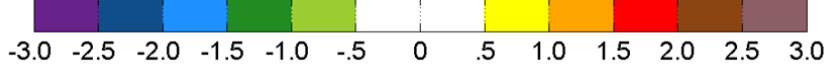

566 Fig. 8 Spatial structures of CEOF2 (explained variance=16.8\%) as a function of time phase 


\section{CEOF2 filt4yr (20.8\%)}

a) $\phi=0^{\circ}$

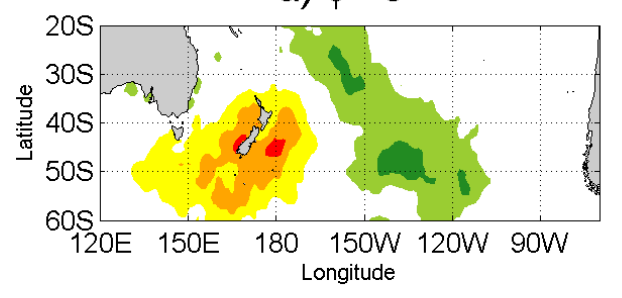

c) $\phi=90^{\circ}$

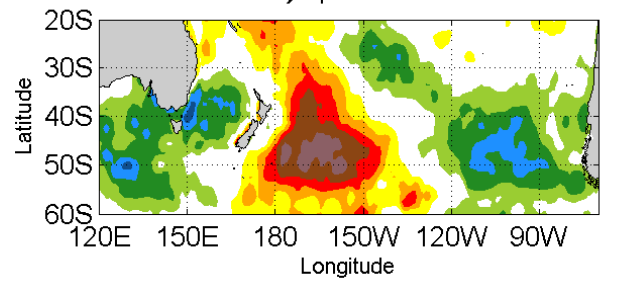

e) $\phi=180^{\circ}$

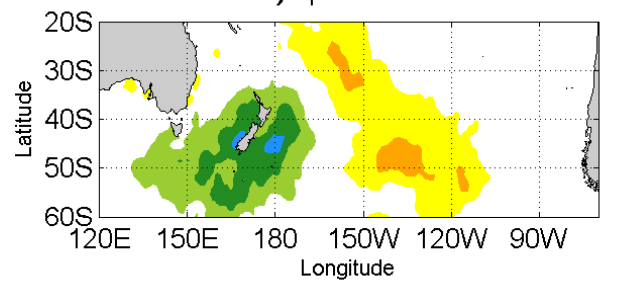

g) $\phi=270^{\circ}$

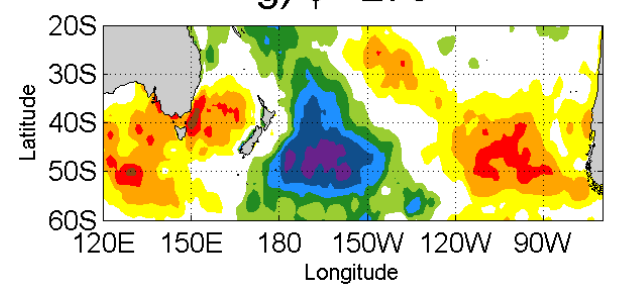

b) $\phi=45^{\circ}$

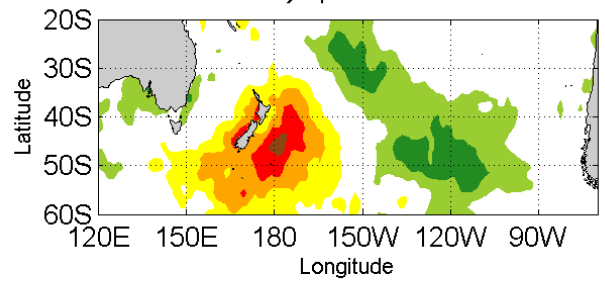

d) $\phi=135^{\circ}$

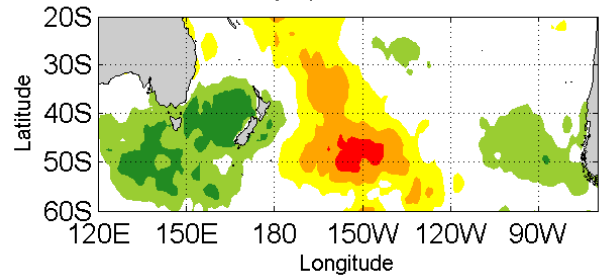

f) $\phi=225^{\circ}$

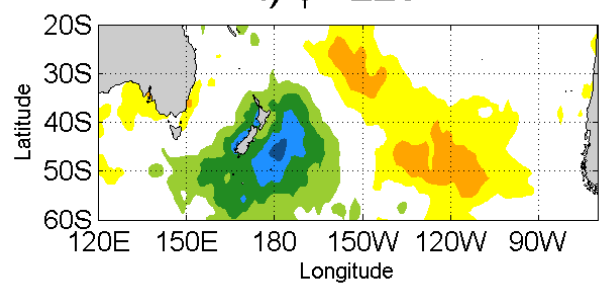

h) $\phi=315^{\circ}$

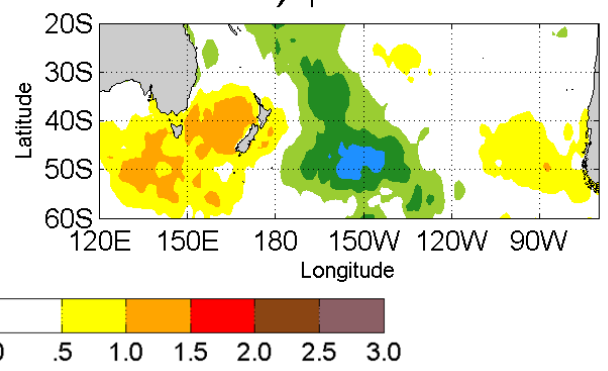

Fig. 9 As in Fig. 8 but using 4-yr filtered SST anomalies. The variance explained by this mode is $20.8 \%$. 


\section{CEOF2 filt7yr (20.4\%)}

a) $\phi=0^{\circ}$

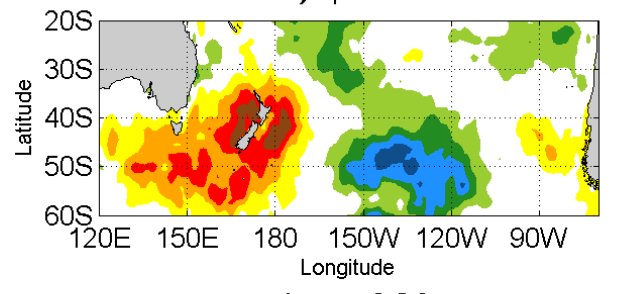

c) $\phi=90^{\circ}$

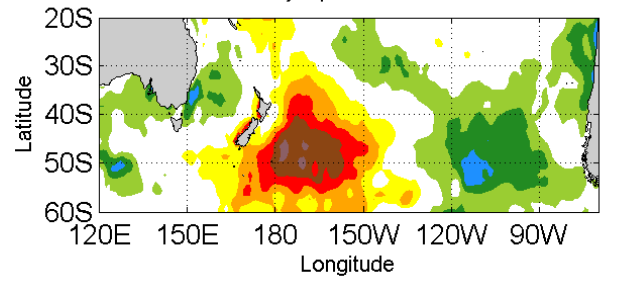

e) $\phi=180^{\circ}$

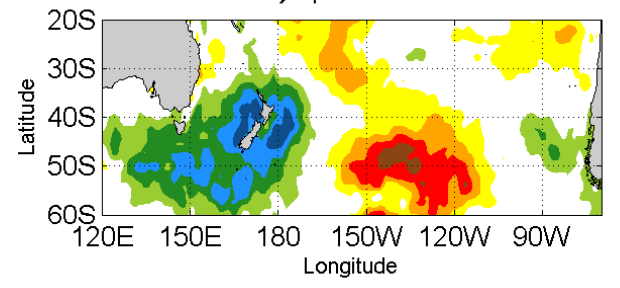

g) $\phi=270^{\circ}$

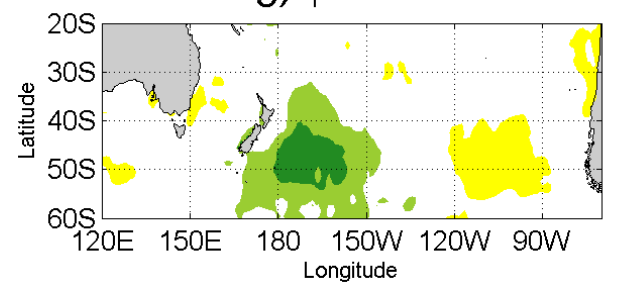

b) $\phi=45^{\circ}$

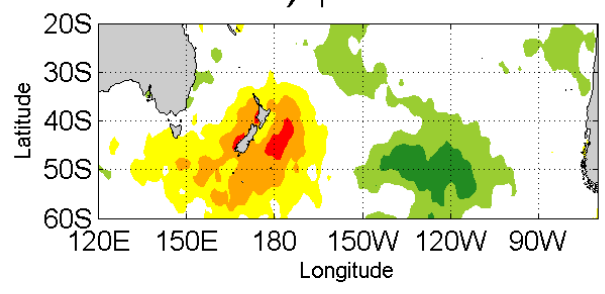

d) $\phi=135^{\circ}$

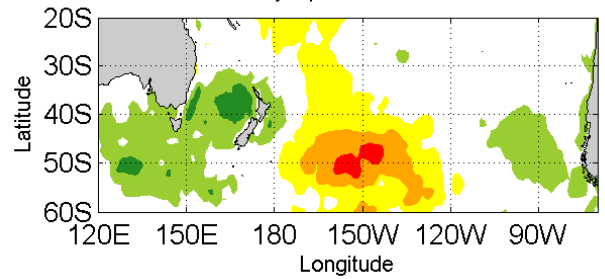

f) $\phi=225^{\circ}$

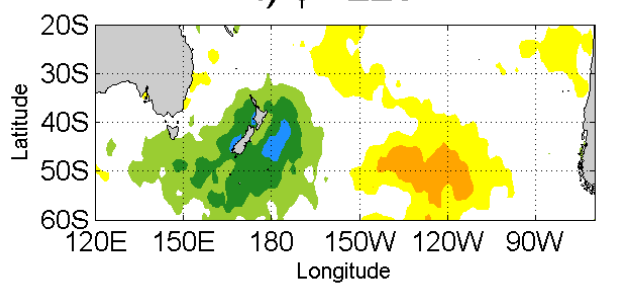

h) $\phi=315^{\circ}$

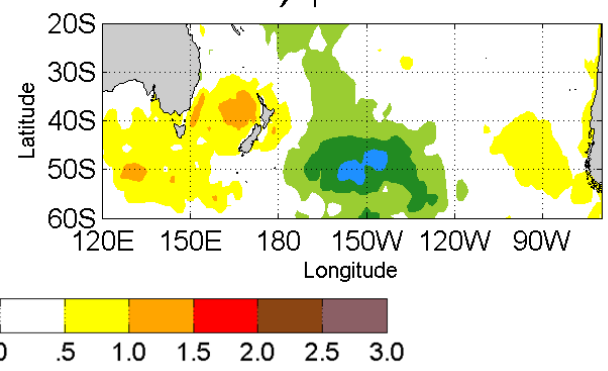

Fig. 10 As in Fig. 8 but using 4-yr filtered SST anomalies. The variance explained by this 
a) CEOF2 unfiltered

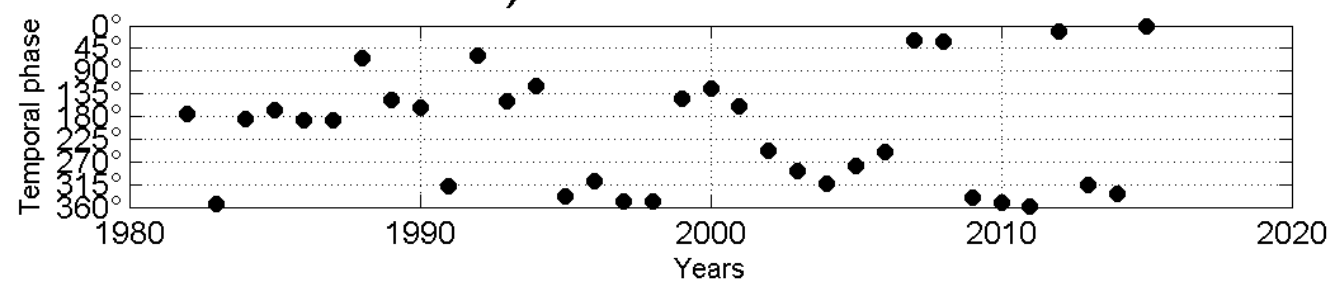

b) CEOF2 filt4yr

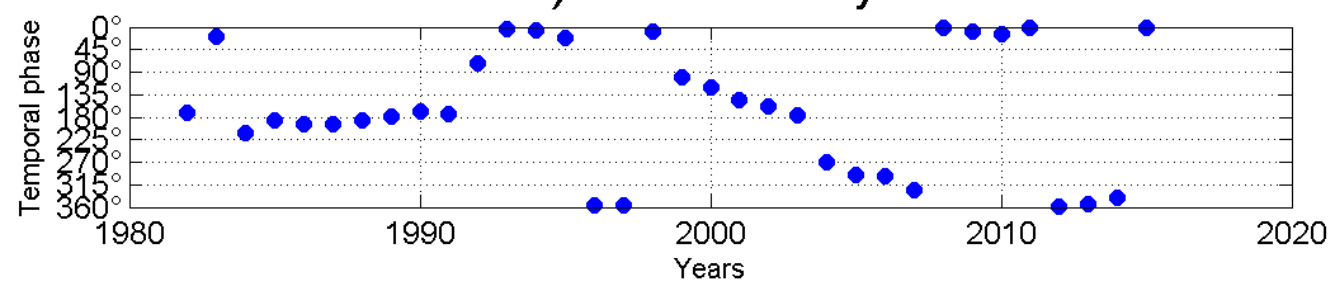

c) CEOF2 filt7yr

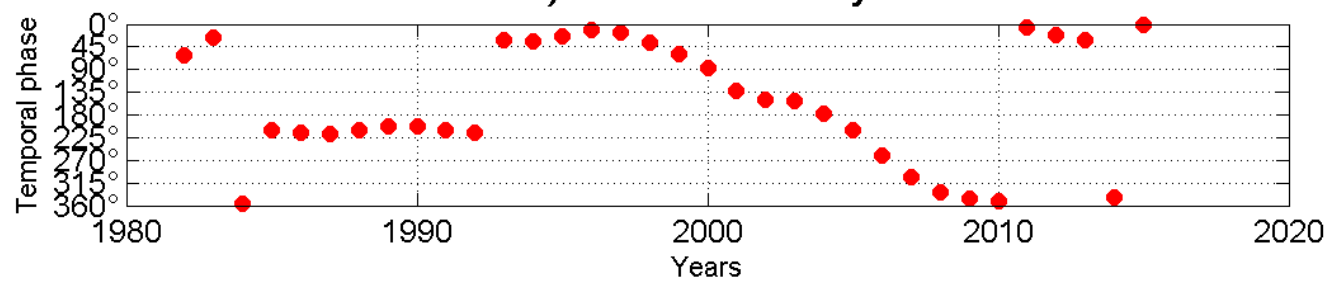

578 Fig. 11 Time evolution of the temporal phase associated with CEOF2 for $(a)$ unfiltered SST 579 anomalies; (b) 4-yr filtered SST anomalies; and (c) 7-yr filtered SST anomalies. The angles 580 of the phase are indicated in the y-axis. 


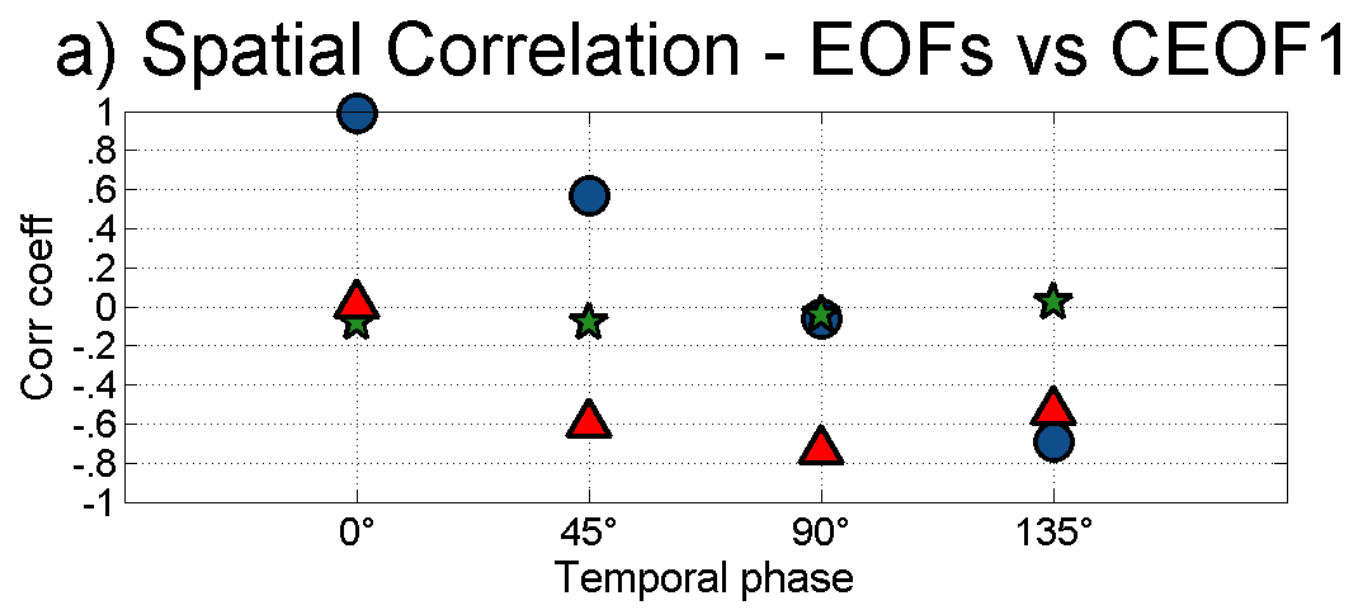

b) Spatial Correlation - EOFs vs CEOF2

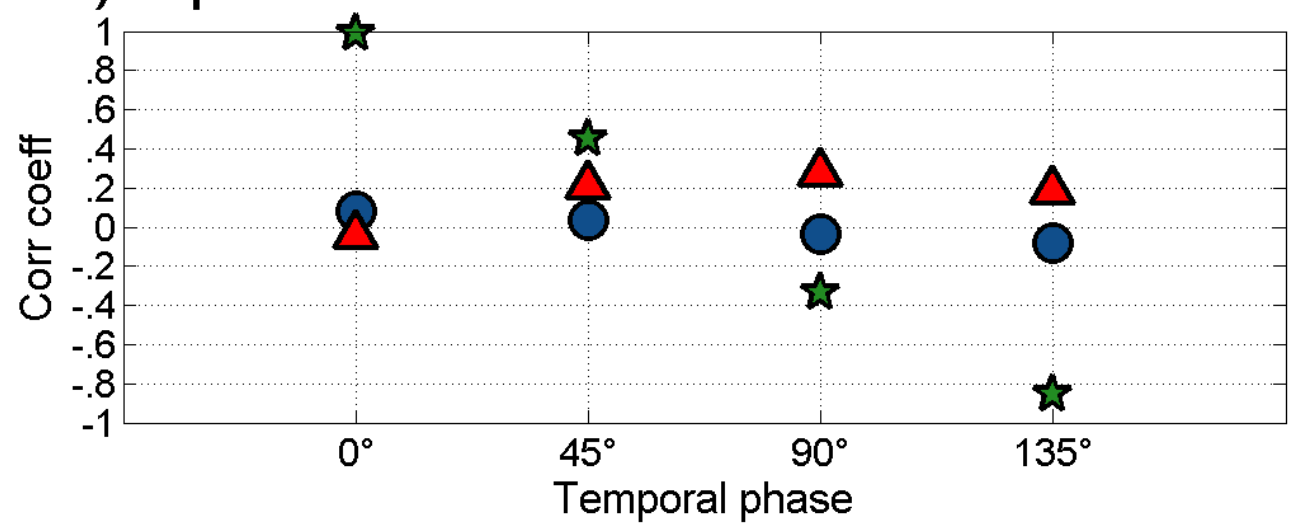

582

583

584

585

586

Fig. 12 Spatial correlation coefficients between the structures associated with (a) CEOF1 and (b) CEOF2 against the patterns of EOF1 (circles), EOF2 (stars) and EOF3 (triangles) at CEOFs phases $\phi=0^{\circ}, 45^{\circ}, 90^{\circ}$ and $135^{\circ}$. 
a) $\operatorname{Corr}(E O F 1$, anom T)

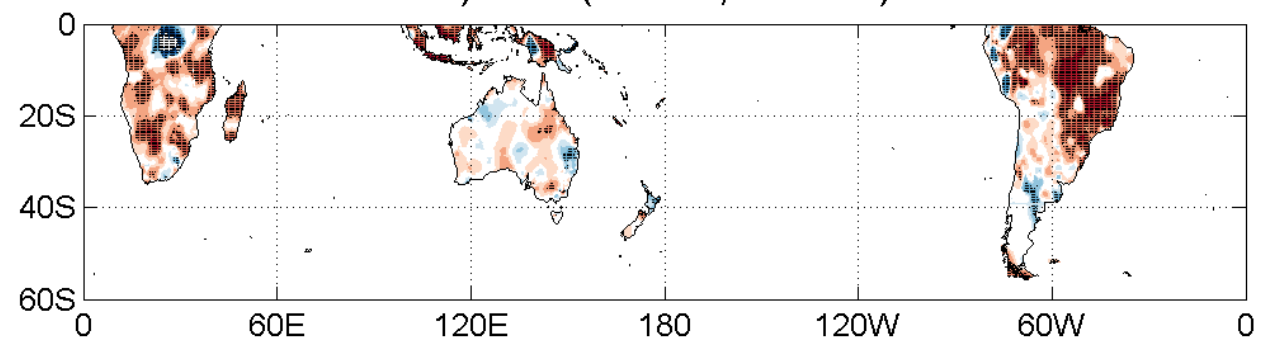

b) Corr(EOF2,anomT)

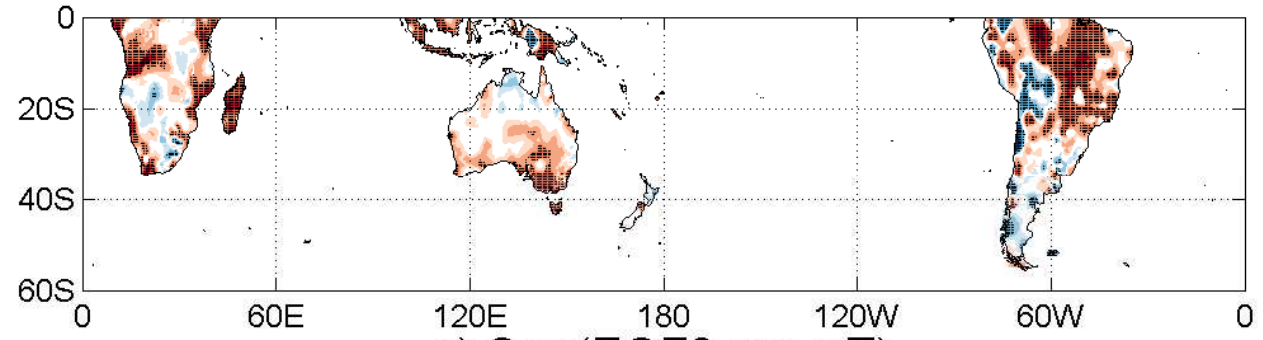

c) Corr(EOF3, anomT)

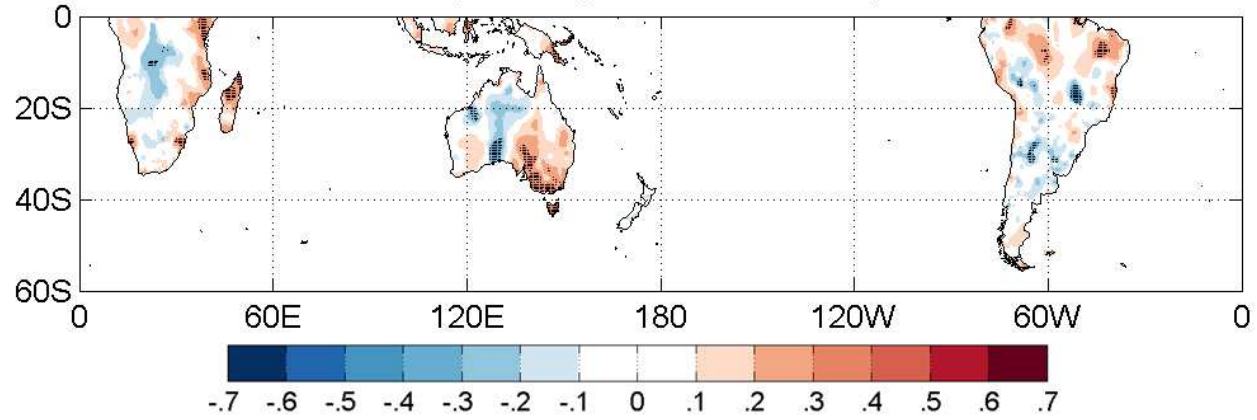

Fig. 13 Correlation coefficients between annual mean anomalies of land surface temperature and $(a) \mathrm{EOF} 1,(b) \mathrm{EOF} 2$ and $(c) \mathrm{EOF} 3$ time series. Black dots indicate correlations are significant at the $10 \%$ level.

591 
a) Corr(EOF1, anomPP)
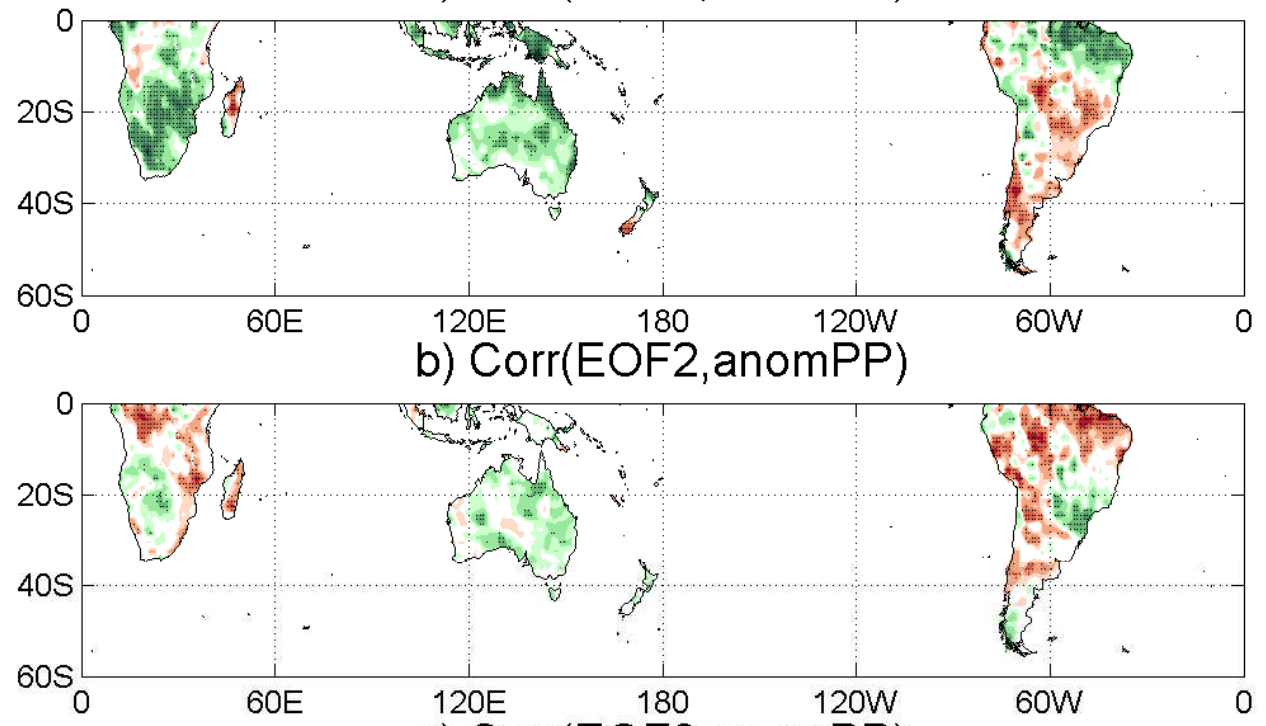

c) Corr(EOF3,anomPP)

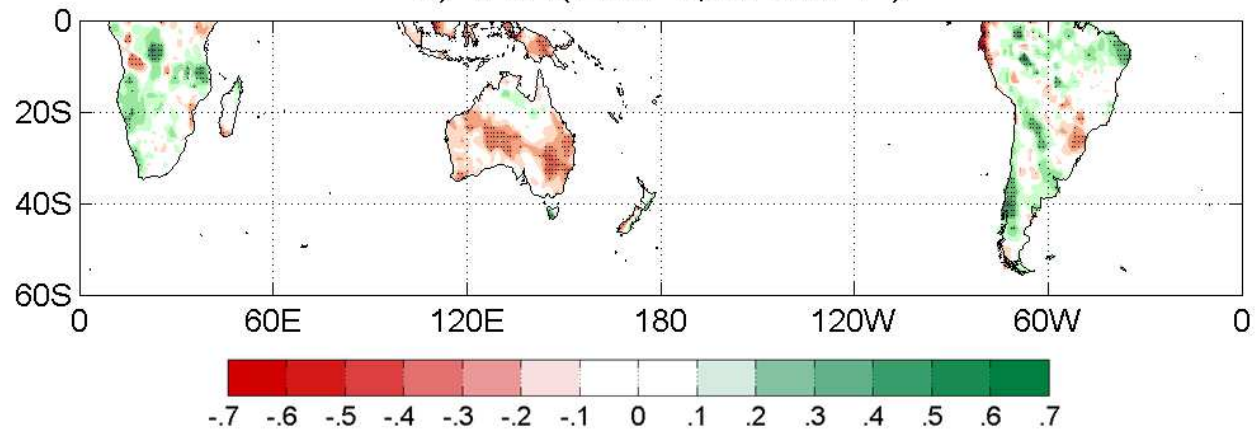

594 Fig. 14 Regression coefficients of annual total land precipitation regressed upon (a) EOF1, 595 (b) EOF2 and $(c)$ EOF3 time series. Units are $\mathrm{mm} \mathrm{yr}^{-1}$ per unit of variation in the amplitude 596 of the PCs. 
a) Temperature trend $\left({ }^{\circ} \mathrm{C} /\right.$ decade $)$

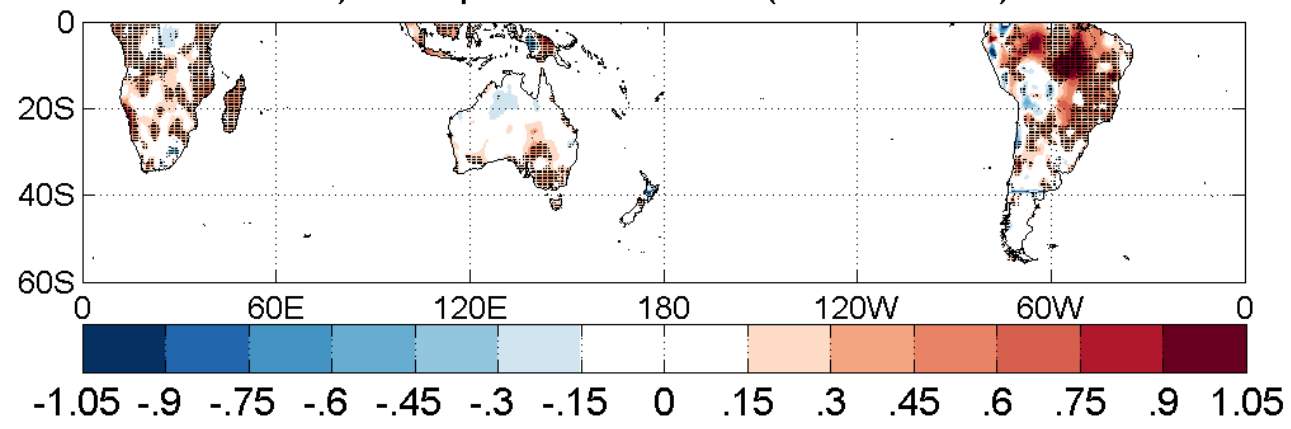

b) Rainfall trend ( $\mathrm{mm} \mathrm{yr}^{-1} /$ decade)

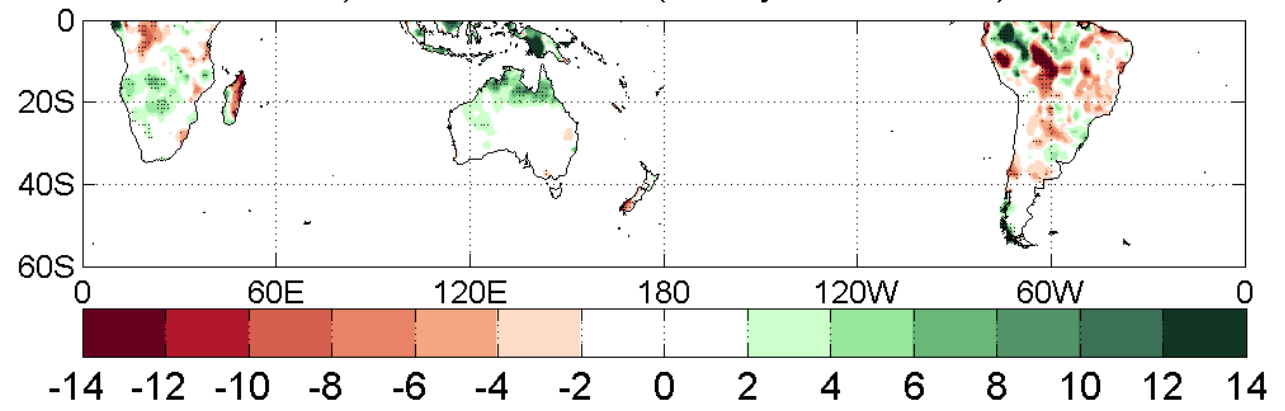

598

599

600

601

602

603
Fig. 15 Observed trends in (a) 2-meter temperature (in ${ }^{\circ} \mathrm{C} /$ decade) and $(b)$ annual precipitation (in $\mathrm{mm} \mathrm{yr}^{-1} /$ decade) during the whole period 1982-2015. Trends that result significantly different from zero at the 5\% confidence level according to a Mann Kendall test are highlighted using black dots. 
a) $\operatorname{Regr}(E O F 1$ vs SLP,TADV)
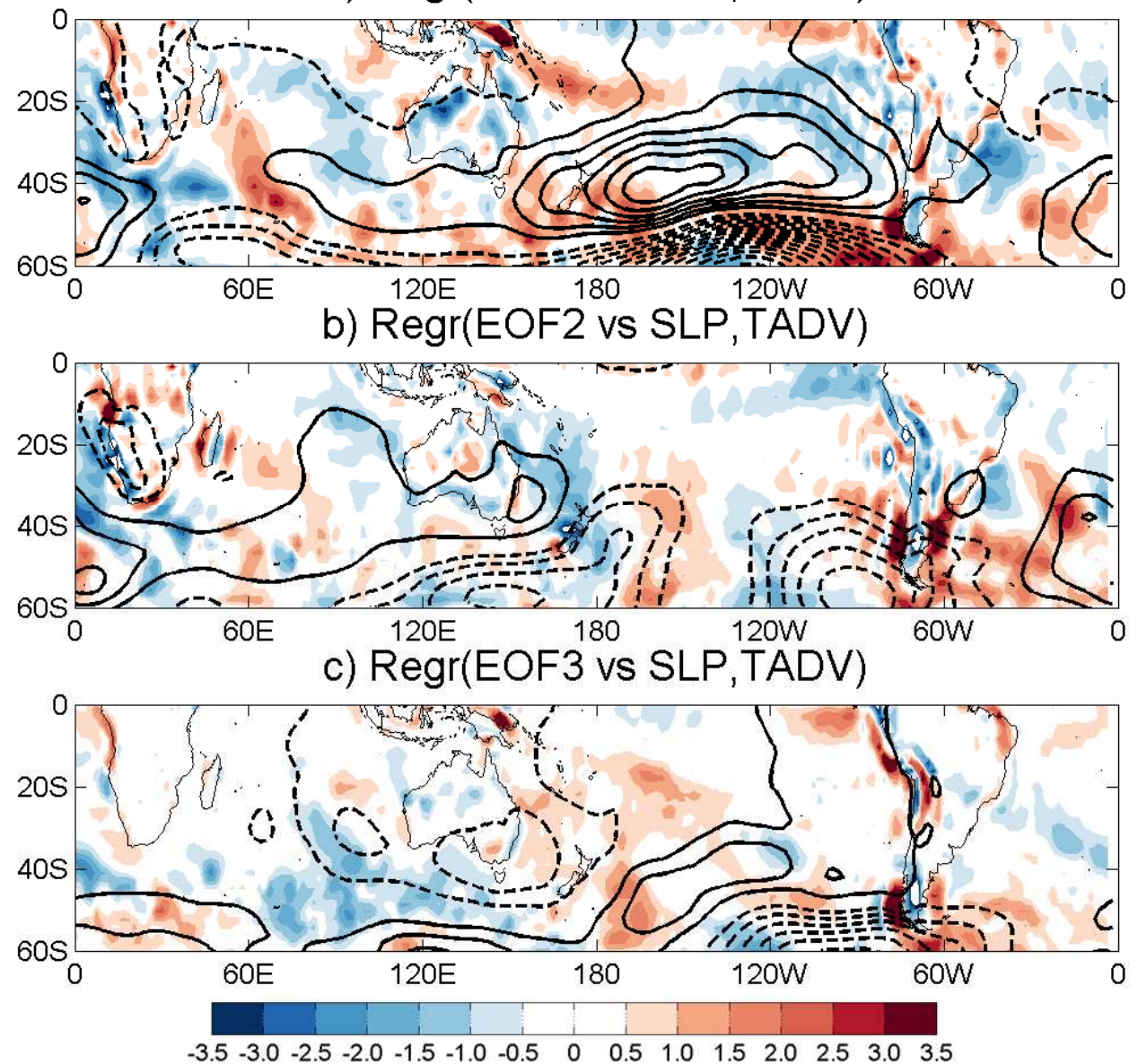

604

605

606

607

608

609

610

Fig. 16 Regression coefficients of anomalies of SLP (lines) and horizontal 2-m temperature advection (shaded) against the time series of ( $a$ ) EOF1, (b) EOF2, and (c) EOF3. Positive (negative) SLP regression coefficients are indicated with full (dashed) lines, every $1 \mathrm{hPa}$, with the zero line omitted. Units are $\mathrm{hPa}$ and $10^{5} \mathrm{~K} \mathrm{~s}^{-1}$ per unit of variation in the amplitude of the PCs. 
611 Table 1 Correlation coefficients between (rows) PC1, PC2 and PC3 and (columns) N3.4 and IPO. Symbols ${ }^{*}$ and ${ }^{\#}$ highlight correlations significant at the $1 \%$ and $5 \%$ level, respectively.

\begin{tabular}{|c|c|c|}
\hline & N3.4 & IPO \\
\hline PC1 & $-0.730^{*}$ & $-0.577^{*}$ \\
\hline PC2 & 0.180 & $-0.422^{\#}$ \\
\hline PC3 & 0.219 & 0.042 \\
\hline
\end{tabular}

614

615 